\title{
Can C-band synthetic aperture radar be used to estimate soil organic carbon storage in tundra?
}

\author{
Annett Bartsch ${ }^{1,2}$, Barbara Widhalm ${ }^{1,2}$, Peter Kuhry ${ }^{3}$, Gustaf Hugelius ${ }^{3}$, Juri Palmtag ${ }^{3}$, and Matthias \\ Benjamin Siewert ${ }^{3}$ \\ ${ }^{1}$ Zentralanstalt für Meteorologie und Geodynamik, 1190 Vienna, Austria \\ ${ }^{2}$ Vienna University of Technology, 1040 Vienna, Austria \\ ${ }^{3}$ Stockholm University, Department of Physical Geography, 10691 Stockholm, Sweden \\ Correspondence to: Annett Bartsch (annett.bartsch@zamg.ac.at)
}

Received: 26 April 2016 - Published in Biogeosciences Discuss.: 3 May 2016

Revised: 4 September 2016 - Accepted: 14 September 2016 - Published: 30 September 2016

\begin{abstract}
A new approach for the estimation of soil organic carbon (SOC) pools north of the tree line has been developed based on synthetic aperture radar (SAR; ENVISAT Advanced SAR Global Monitoring mode) data. SOC values are directly determined from backscatter values instead of upscaling using land cover or soil classes. The multi-mode capability of SAR allows application across scales. It can be shown that measurements in $\mathrm{C}$ band under frozen conditions represent vegetation and surface structure properties which relate to soil properties, specifically SOC. It is estimated that at least $29 \mathrm{Pg} \mathrm{C}$ is stored in the upper $30 \mathrm{~cm}$ of soils north of the tree line. This is approximately $25 \%$ less than stocks derived from the soil-map-based Northern Circumpolar Soil Carbon Database (NCSCD). The total stored carbon is underestimated since the established empirical relationship is not valid for peatlands or strongly cryoturbated soils. The approach does, however, provide the first spatially consistent account of soil organic carbon across the Arctic. Furthermore, it could be shown that values obtained from $1 \mathrm{~km}$ resolution SAR correspond to accounts based on a high spatial resolution $(2 \mathrm{~m})$ land cover map over a study area of about $7 \times 7 \mathrm{~km}$ in NE Siberia. The approach can be also potentially transferred to medium-resolution C-band SAR data such as ENVISAT ASAR Wide Swath with $\sim 120$ m resolution but it is in general limited to regions without woody vegetation. Global Monitoring-mode-derived SOC increases with unfrozen period length. This indicates the importance of this parameter for modelling of the spatial distribution of soil organic carbon storage.
\end{abstract}

\section{Introduction}

The quantification of presently stored soil organic carbon (SOC) in the Arctic is of high interest for the assessment of climate change impacts in this environment (Schuur et al., 2008). These carbon pools are prone to changes, specifically increasing temperatures which are predicted for large proportions of the Arctic. Degradation of the underlying permafrost may induce environmental changes that trigger or accelerate the release of greenhouse gases at a scale that its impact is expected to be relevant to the global climate (Schuur et al., 2015).

The Northern Circumpolar Soil Carbon Database (NCSCD) by Tarnocai et al. (2009) and recently updated in Hugelius et al. (2013) currently provides the only basis for circumpolar accounts of soil organic carbon storage. Accounts for carbon stored in soils down to $3 \mathrm{~m}$ depth and additional stocks of sediments with various thicknesses are included. It relies on regionally differing information sources, including soil maps. This leads to differences in accuracies across the Arctic and upscaling artifacts. Uncertainties in the SOC estimates for the northern permafrost region are large (Tarnocai et al., 2009).

SOC can be derived from remotely sensed data using soil colour as an indicator (Wulf et al., 2015). The assumption is that SOC is related to wetness which influences the soil colour. But this approach is only applicable in cases without vegetation cover. A further method is the combination of in situ measurements with land cover maps. Soil carbon and nitrogen upscaling down to a depth of $100 \mathrm{~cm}$ based 
on land cover maps has been shown feasible at the site scale (Hugelius et al., 2011; Palmtag et al., 2015; Siewert et al., 2015). Detailed, site-specific land form and/or land cover classification schemes using high-resolution satellite data have been applied. The method can be used to provide a weighted "landscape-level" mean for the entire study area, for which a single SOC value is attributed to each recognized thematic class. Spatially explicit variations within a certain class and transitions cannot be derived.

The major constrain for upscaling to circumpolar scale with such a method is the insufficient thematic detail of existing land cover datasets (e.g. Widhalm et al., 2015a). An approach which makes use of satellite data available at multiple scales is required for the upscaling to larger regions and up to circumpolar levels. One option would be the development of a land cover dataset which includes the required thematic detail in order to represent the range of carbon stocks across the high latitudes. A geospatial product which has been proven applicable for many studies is the Circumpolar Arctic Vegetation Map (CAVM) by Walker et al. (2002). It shows the types of vegetation that occur across the Arctic, between the ice-covered Arctic Ocean to the north and the northern limit of forests to the south. It is, however, designed to map vegetation communities rather than soil types. Ping et al. (2008) used the CAVM to derive four distinct landscape units in order to upscale SOC for North America north of the tree line. A wide range of SOC stock values have been observed for landscape unit averages due to environmental gradient effects. A direct relationship between the normalized difference vegetation index (NDVI) and SOC has been found for the high Arctic (Horwath Burnham and Sletten, 2010) but has not been shown applicable outside that region. An alternative approach for direct derivation of SOC values is required which can represent gradients and is applicable for the entire Arctic and subarctic domain.

The land cover types which are of interest differ in surface structure, including vascular plant cover as well as in microtopographic relief (e.g. tussocks and hummocks). Such features can be captured with active microwave data depending on frequency and polarization. The signal interacts with these surfaces and a certain proportion is directed back to the sensor. The backscatter intensity can be thus used to obtain information about the surface properties. Radar satellite data are available at different scales (metres to kilometres) based on usage of the synthetic aperture radar (SAR) principle. A limitation of high- to medium-resolution applications is the variable coverage (Bartsch et al., 2009, 2012). ENVISAT ASAR data acquired in Global Monitoring mode are, however, available circumpolar, spanning several years (Bartsch et al., 2009; Widhalm et al., 2015a) with approximately $1 \mathrm{~km}$ resolution. An additional advantage of such data is the illumination independence. A challenge is the complexity of the interaction of the signal with the Earth surface. Water content of the near-surface soil contributes to the backscatter during unfrozen periods (Wagner et al., 1999; Pathe et al.,

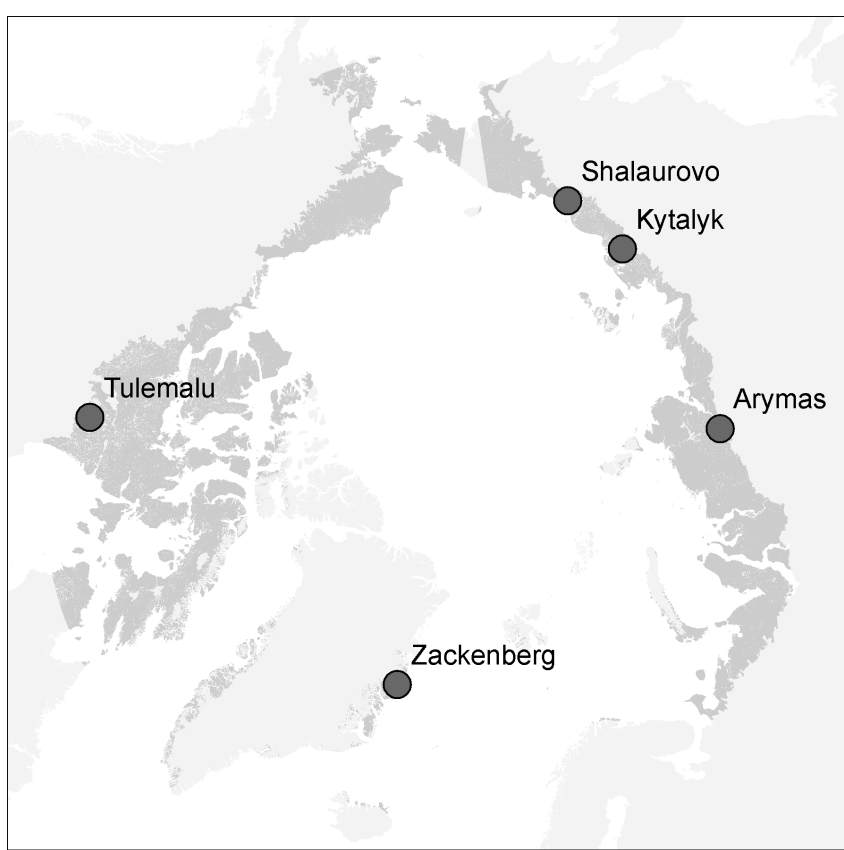

Figure 1. Location of field sites with high-resolution land-coverbased soil organic carbon maps (Table 1) and area covered by the Circumpolar Arctic Vegetation Map (CAVM; Walker et al., 2002) as well as ENVISAT ASAR GM data (medium grey)

2009) as well as snow grains in the wintertime (Ulaby et al., 1982). The impact of the latter is, however, limited during early winter, when snow cover is low and metamorphosis of snow grains is negligible at $\mathrm{C}$ band (Naeimi et al., 2012). Such data are available not only from SAR but also from the much coarser spatial resolution scatterometer data. Applications across scale and instruments are common. ENVISAT ASAR data acquired in Wide Swath (WS, 120 m) and Global Monitoring (GM, $\sim 1 \mathrm{~km}$ ) mode were used, for example, to downscale soil-moisture-related patterns (Wagner et al., 2008; Pathe et al., 2009) or bias-correct (Högström and Bartsch, 2016) information from scatterometer. The applicability of similar multitemporal analyses for both GM and WS data has already been demonstrated for forest growing stock volume retrieval (Santoro et al., 2011). WS data resampled to GM resolution are also suggested as a substitute in the case of missing GM records. In this study it is hypothesized that a relationship exists between SOC and the $\mathrm{C}$-band radar backscatter resulting from surface roughness in tundra regions which is valid for SAR data acquired at different spatial resolutions. The aim is to provide a circumpolar consistent account of SOC which also provides information on gradients. Field measurements of SOC- and land-covermap-based upscaling results are used and results are crosscompared to externally available soil type information (NCSCD and in situ) as well as satellite-derived and potentially related parameters (vegetation and growing season length). 


\section{Datasets}

\subsection{Synthetic aperture radar data}

The ASAR (Advanced Synthetic Aperture Radar) instrument on board ESA's ENVISAT satellite operated in C band $(5.3 \mathrm{GHz})$ in five different modes, with temporal and spatial resolution varying from $30 \mathrm{~m}$ to $1 \mathrm{~km}$ from 2002 to spring 2012. Among these modes, the GM mode formed the background mission and was active whenever no other mode had been requested. GM data were obtained using the ScanSAR technique and provided low-resolution images $(1 \mathrm{~km})$ with a wide swath width of $405 \mathrm{~km}$ and incidence angles ranging from 15 to $45^{\circ}$ (ESA, 2004). These data became accessible starting from 2005. Data availability in the Arctic is high (Bartsch et al., 2009) due to overlapping swaths related to the polar orbit and low demand of higher-resolution acquisitions in these regions. All ASAR GM level $1 \mathrm{~b}$ data used have been acquired with $\mathrm{HH}$ polarization (horizontally - with respect to the Earth surface - transmitted and received). They are gridded to $500 \mathrm{~m} \times 500 \mathrm{~m}$.

For the study area Kytalyk (NE Siberia), ENVISAT ASAR data acquired in WS mode and HH polarization have also been tested. These data cover the same incidence angle range and swath but spatial resolution is finer, although still medium, with $\sim 120 \mathrm{~m}$ (Closa et al., 2003). Data availability of this mode is lower since it was acquired on request only. They are commonly gridded to $75 \mathrm{~m} \times 75 \mathrm{~m}$ (e.g. Bartsch et al., 2007; Santoro et al., 2011; Reschke et al., 2012).

\subsection{Soil organic carbon data}

In situ measurements of SOC used in this study have been collected from five different sites across the Arctic: Shalaurovo, Kytalyk and Arymas in Siberia; Zackenberg in Greenland; and Tulemalu in Canada (Fig. 1). All are located within the tundra biome and are characterized by continuous permafrost terrain. For these sites, the investigated SOC depth increments are $0-5,0-30$ and $0-100 \mathrm{~cm}$. Two types of input data are used. Soil pedon point data and maps of SOC derived from thematic upscaling of the soil pedon data using high to very high resolution optical satellite and airborne data (Palmtag et al., 2015; Siewert et al., 2015; Hugelius et al., 2010). In order to obtain these maps, collected soil pedons were grouped according to the thematic classes in these schemes. Simple arithmetic means and standard deviations were then calculated for each SOC storage depth increment per thematic class (and for the calculation of $0-30$ and $0-100 \mathrm{~cm}$ SOC stocks). These means were subsequently weighted by the proportional representation of each thematic class in the study area in order to arrive at a weighted "landscape-level" mean for the entire study area. Statistical uncertainties in this type of approach are described in Hugelius (2012).

Fourteen thematic classes (partially with subclasses for grasslands and fens) based on the classes from the local land cover classifications are distinguished across the Arctic for this study. The SOC stocks in the upper 30 and $100 \mathrm{~cm}$ of the soil for certain classes from different sites differ from each other since they have been adjusted site by site. SOC values range from almost $0 \mathrm{~kg} \mathrm{~m}^{-2}$ at alpine and barren ground locations to more than $80 \mathrm{~kg} \mathrm{~m}^{-2}$ for peat bogs. The maximum of non-peat sites is approximately $35 \mathrm{~kg} \mathrm{~m}^{-2}$ for $100 \mathrm{~cm}$ and $15 \mathrm{~kg} \mathrm{~m}^{-2}$ for $30 \mathrm{~cm}$. Table 1 provides further details and the data sources and land cover map thematic content.

The Northern Circumpolar Soil Carbon Database (NCSCD) by Hugelius et al. $(2013,2014)$ provides SOC stocks in the circumpolar permafrost region. The NCSCD is a polygon-based digital database compiled from harmonized regional soil classification maps in which data on soils have been linked to pedon data from the northern permafrost regions to calculate SOC content and mass. It includes SOC values for $0-30,0-100,0-200$ and $0-300 \mathrm{~cm}$. For this study, only the NCSCD area north of the Arctic tree line as defined in the CAVM (Walker et al., 2002) is considered.

\section{Methodology}

\subsection{Background}

Radar backscatter is dependent on sensor parameters such as incidence angle, polarisation and wavelength as well as target parameters like surface roughness and vegetation structure as well as dielectric properties (Ulaby et al., 1982). Roughness and permittivity are the governing factors in the case of bare soil (Oh et al., 1992). The dielectric constant highly depends on moisture content, leading to higher backscatter values in the microwave range under wet soil conditions (Woodhouse, 2006). Regions with soil conditions close to saturation near the surface can be therefore identified using SAR data. This has been demonstrated applicable for peatland detection at high latitudes with C band (Bartsch et al., 2007, 2009; Reschke et al., 2012). The wet and at the same time high SOC areas have a low bulk density over several tens of centimetres and are water/ice-rich (more than $60 \%$ at, for example, Kytalyk, Weiss et al., 2016)

The dielectric constant is significantly lower under frozen conditions. Frozen soils cause therefore similar backscatter like dry soils which has been specifically exploited for Cband applications (e.g. Wagner et al., 1999; Park et al., 2011). Winter backscatter is thus determined by the above-surface remains of vascular plants, surface roughness, near-surface soil texture and, if present, also snow cover. The last of these has little influence in early winter (Naeimi et al., 2012). Interaction of C-band signals with snow are lower than for shorter wavelengths (Ulaby and Stiles, 1981). The signal may also penetrate a few centimetres into the soil. In undisturbed environments (no buildings or agriculture) it can be assumed that scattering is governed by soil type and vegetation cover. The influence of vascular plants on signal interaction is, however, 

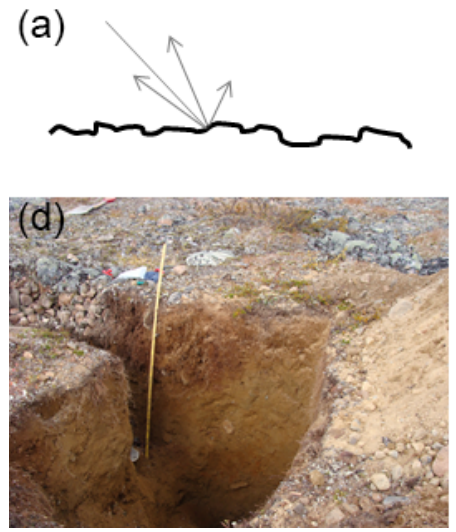

(b)
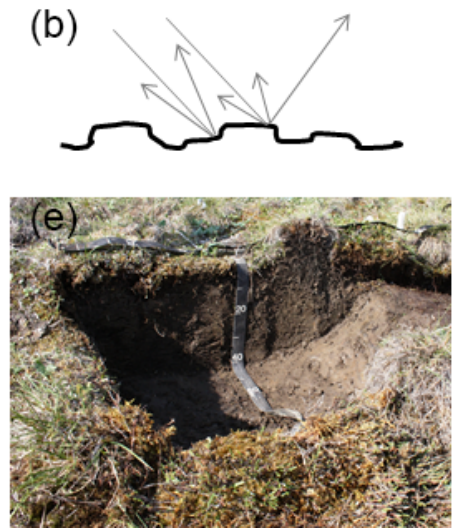

(c)
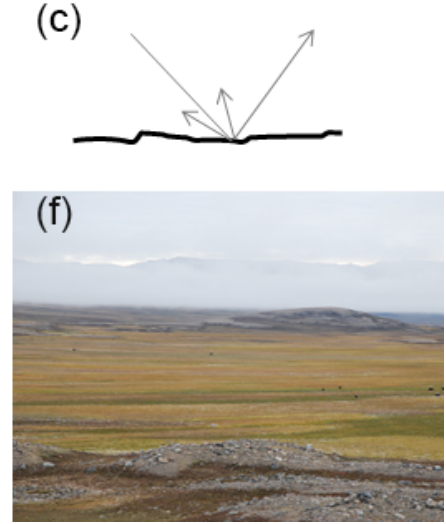

Figure 2. Top: sketch of scattering from different surfaces. The length of the arrows represents the backscatter intensity: left - rough surface with, for example, pebbles at the surface; middle - surface with partial high and low signal return; right - smooth surface with almost specular reflection (adapted from ESA 2004). Bottom: photographs (G. Hugelius) representing different roughness and soil carbon types: left - soil pit in carbon-poor landscape; middle: hummocky carbon-rich soil profile across the active layer of a frost boil; right: carbon-poor slope in the front and carbon-rich valley in the background (Zackenberg).

Table 1. Available SOC data upscaled from high-resolution remotely sensed data.

\begin{tabular}{lllll}
\hline Site name & Upscaling source & Harmonized land cover classes & Source & Pedon data \\
\hline Kytalyk & QuickBird & grass, willow, fen, other, tussock & (Siewert et al., 2015) & 21 \\
Zackenberg & Airborne Hyperspectral & grass, heath, willow, fen, fell, boulder, other & (Palmtag et al., 2015) & 24 \\
Shalaurovo & QuickBird & grass, willow, fen, tussock & (Palmtag et al., 2015) & 18 \\
Tulemalu & Landsat 7 ETM+ & dry, moist and wet tundra, fen, bog & Hugelius et al. (2010) & 35 \\
Arymas & QuickBird & grass, willow, trees, fen, dry tundra & Palmtag et al. (2016) & 35 \\
\hline
\end{tabular}

limited at $\mathrm{C}$ band (approximately $5.6 \mathrm{~cm}$ wavelength; Waring et al., 1995). Surface roughness thus plays an important role for spatial differences in backscatter during frozen conditions in tundra regions. Specifically, data acquired in $\mathrm{HH}$ (horizontally sent and received) polarization are expected to represent soil conditions better than VV (vertically sent and received) polarization (Brown et al., 2003). Vertically (with respect to the Earth surface) polarized waves interact more with vertically structured vegetation parts (stems) than horizontally polarized waves. $\mathrm{HH}$ as well as $\mathrm{HV}$ polarizations are thus more sensitive to roughness than $\mathrm{VV}$ polarizations (Holah et al., 2005).

It has been shown for C band (Jagdhuber et al., 2014) that volume scattering (at anisotropic particles) dominates for peatland soil during unfrozen conditions and it changes to surface scattering when frozen. The dielectric contrasts between scattering components decrease, and surface roughness indeed determines the magnitude of backscatter.

Tundra and in general wetland environments are commonly classified based on non-frozen period data when SAR data are employed. There are to date only very few studies which make use of frozen period acquisitions (Duguay et al., 2015; Widhalm et al., 2015a). The advantage for using winter data is that only roughness and volume scattering contributes to the return signal intensity. In addition, during summer, there is the influence of liquid water. High C-band backscatter areas are therefore often open wetlands (especially peatlands; e.g. Bartsch et al., 2009; Reschke et al., 2012) but can be also areas with high roughness and/or volume scattering. Locations with higher soil organic carbon (SOC) are areas with low roughness (with respect to $\mathrm{C}$ band, $5.6 \mathrm{~cm}$ wavelength). They have a smoother surface than drier low-carbon sites in the high Arctic, which leads to the hypothesis that C-band backscatter can be used as a proxy for SOC content (Fig. 2).

Interaction of the C-band signal with snow grains needs to be accounted for. There is especially an impact when ice crusts form (Naeimi et al., 2012; Bartsch, 2010). Backscatter does increase in such cases. $\mathrm{C}$ band is, however, less sensitive to snowpack changes than shorter wavelengths (e.g. Ku band; Bartsch, 2010). Backscatter can increase during the course of the winter by about $1 \mathrm{~dB}$ at some locations (Naeimi et al., 2012). In a case study for Yakutia, no increase in ASAR GM backscatter with increasing SWE (snow water equivalent) could be observed (Park et al., 2011). In order to account for possible contributions by snow cover, (1) only December data should be used, assuming that there are frozen conditions and snow depth is still limited, and (2) the minimum from as many years as possible should be calculated in order 
to have the lowest possible impact (this also accounts for the GM-specific noise).

\subsection{SAR data processing}

First, automatic geocoding and radiometric calibration were performed. The SAR Geophysical Retrieval Toolbox (SGRT, Vienna University of Technology; Sabel et al., 2012) was used for the required preprocessing of the ENVISAT ASAR GM level $1 b$ data. This is a collection of routines which manages SAR geocoding and radiometric calibration by calling other non-commercial and commercial software packages. By incorporating orbit information (DORIS (Doppler Orbitography and Radiopositioning Integrated by Satellite) orbit files) and digital elevation data (US Geological Survey GTOPO30 digital elevation model, improved by Shuttle Radar Topography Mission data), geocoded images were produced with sub-pixel accuracy (Park et al., 2011; Pathe et al., 2009). The data are resampled into a fixed 15 arcsec grid (datum WGS-84), within $0.5^{\circ}$ by $0.5^{\circ}$ tiles, to allow for efficient spatial and temporal analysis. The data $(>8000$ scenes north of $60^{\circ} \mathrm{N}$ ) was normalized to a reference angle of $30^{\circ}$ by fitting a linear model to the backscatter data (Pathe et al., 2009; Sabel et al., 2012) in order to remove the influence of local incidence angle on radar backscatter. The model provides an estimate of the slope in units of decibels per degree of incidence angle, which characterizes the decrease in the radar backscatter from near range to far range. The model is calibrated for each pixel separately using the acquisitions from overlapping orbits (Wagner et al., 2008). No data can be processed with the tools used for orthorectification (SGRT) for scenes which cross the dateline. This leads to a data gap in the Russia Far East. The dataset was eventually resampled to a grid with polar stereographic projection with $500 \mathrm{~m} \times 500 \mathrm{~m}$ pixel size.

On average, 45 December acquisitions were available per pixel. Since GM data exhibit comparably high noise (Park et al., 2011), temporal and/or spatial statistical measures (averaging, filtering etc.) need to be applied. The mean value could be used in order to account for noise alone. There are, however, also other effects that need to be accounted for, especially snow-related changes such as the formation of ice layers due to rain on snow. They would increase the backscatter, but they are not expected to be present in all years at that time of the year. The usage of the minimum backscatter value (from several years) reduces the probability that structure change affects the backscatter dataset used for SOC retrieval. The minimum of the entire record for each pixel was therefore calculated in this study instead of single values representing a certain date. Summer (July and August) data have been processed in addition for the Kytalyk site and mean values derived. This dataset is used to exemplify the advantage of using winter data opposed to summer records. Data are derived as sigma nought and converted to decibels. The dataset has been masked for lakes and glaciers based on the map classes of the Global Lakes and Wetlands Database (Lehner and Döll, 2004) and GlobCover (Bicheron et al., 2008), as well as for tree line (Walker et al., 2002).

\subsection{Determination of relationship between backscatter and SOC}

The C-band backscatter is directly compared to locally upscaled SOC maps and underlying pedon (point) data (Table 1, Fig. 1). Neither all classes nor the full range of SOC values can be found at single sites. A region with lower SOC (Zackenberg) and a site with medium to high values (Kytalyk) are therefore used in combination to obtain a representative range for the establishment of the empirical relationship for upscaling. The maps of the remaining sites have been used for validation.

Zonal mean values (a zone refers to a land cover class) have been extracted for the SOC classes available for Kytalyk and Zackenberg for model calibration. The advantage of the zonal mean as opposed to the pedon (point) data is that the scale is comparable to the $1 \mathrm{~km}$ resolution GM data.

The Pearson correlation has been derived for the zonal means and thereafter a function determined by least-squares regression. The obtained function has been subsequently applied to the circumpolar dataset. The land-cover-based SOC maps available from Tulemalu, Arymas and Shalaurovo have been used for validation. Regional differences have been assessed using the soil-map-based NCSCD (v2.2) by Hugelius et al. (2013), which has been converted to a $500 \times 500 \mathrm{~m}$ gridded dataset with separate layers for each SOC class and percentages of the soil types turbel, histel and histosols. This dataset has not been applied for training since it is based on different types of data sources around the Arctic. The impact of soil type on the SOC retrieval is, in addition, investigated using the information available from the original pedon (point) information from all study sites since this information is not preserved in the land cover classifications.

\subsection{Circumpolar evaluation}

The validity of the approach to the tundra area is also assessed with satellite records of vegetation (NDVI) and unfrozen period length (as obtained from Metop ASCAT; Naeimi et al., 2012; Paulik et al., 2012). MODIS NDVI data were retrieved from the online data pool, courtesy of the NASA Land Processes Distributed Active Archive Center (LP DAAC), USGS/Earth Resources Observation and Science (EROS) Center, Sioux Falls, South Dakota (https: //lpdaac.usgs.gov/dataaccess/datapool). The NDVI records have been re-classified to represent ranges of 0.05 for each class. The number of unfrozen days has been aggregated for each available year (2007-2013) and averaged for the available time period. The average SOC values from the GM approach as well as from the NCSCD have been extracted for each NDVI and unfrozen period length class. Wetness level 

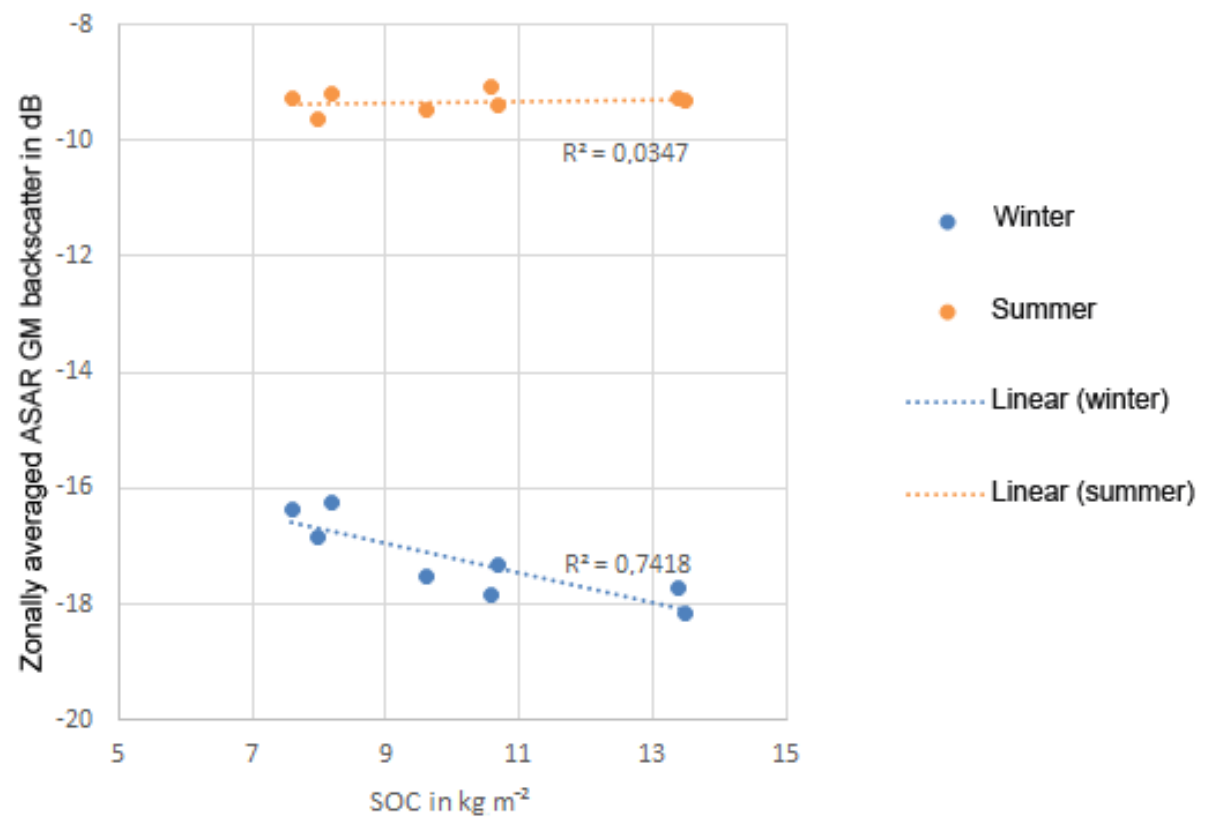

Figure 3. SOC from land cover classifications $(0-30 \mathrm{~cm})$ versus winter and summer backscatter from ENVISAT ASAR GM for Kytalyk.

classes based on C-band radar backscatter ranges as defined in Widhalm et al. (2015a) are also converted into SOC and discussed.

\subsection{Transfer of the approach to WS data}

The higher spatial resolution (but lower sampling rate and inconsistent coverage) data from ENVISAT ASAR WS (also HH polarization) have been used in order to test the transferability of the approach across scales for the Kytalyk study site in NE Siberia. Due to the limited data availability, normalization cannot be applied as for the GM data (approach by Wagner et al., 2008; Sabel et al., 2012). Sabel et al. (2012) and Wagner et al. (2008) exploit the availability of a representative range of incidence angles for a certain location by using acquisitions from several overlapping orbits. A conventional method which corrects for local terrain-related effects only (as available with the free NEST toolbox by the European Space Agency) has been used instead. The radiometric normalization available with NEST only accounts for terrain effects. This leads to a location-specific bias with respect to the circumpolar GM-based dataset. It was therefore required to adjust the WS data to the value range of the GM dataset. The incidence angle differs, however, by less than $0.1^{\circ}$ across the Kytalyk and Zackenberg sites. A single offset value per site can be therefore used to adjust the WS backscatter to GM. It has been derived from the average regional backscatter of both datasets.

\section{Results}

\subsection{SOC determination}

No relationship $\left(R^{2}=0.03\right)$ can be found for the SOC zones at Kytalyk in the case of comparison to summer backscatter as soil moisture adds to the backscatter of the wetter (and at the same time higher SOC) sites. This differs for winter data. The higher the SOC, the lower the winter backscatter $\left(R^{2}=0.74\right)$ since it excludes the soil moisture effect (Fig. 3).

The range of decibels of the GM data which represents the SOC values in the reference datasets is about $8 \mathrm{~dB}$ for land cover class averages and almost $10 \mathrm{~dB}$ for pedon data. An $R^{2}$ of 0.86 was determined for the linear relationship between backscatter of GM data and SOC of $0-30 \mathrm{~cm}$ from SOC maps of Kytalyk and Zackenberg derived from land cover unit (Fig. 4). Only $82 \%$ of the variation can be explained in the case of SOC $0-100 \mathrm{~cm}$. SOC variation for $5 \mathrm{~cm}$ depth cannot be resolved with the C-band data.

Average/maximum SOC for the CAVM domain reaches $7.4 / 14 \mathrm{~kg} \mathrm{~m}^{-2}$ for $30 \mathrm{~cm}$ and $19.6 / 36 \mathrm{~kg} \mathrm{~m}^{-2}$ for $100 \mathrm{~cm}$ (Fig. 5a and b) when the linear models are applied to the entire GM dataset.

Similar coefficients of determination can be obtained using WS data (Fig. 6). The linear relationship for GM and SOC is also valid for the higher spatial resolution WS data however, only after offset correction. Furthermore, we cannot rule out the possibility that snow conditions with ice layers (leading to higher backscatter) are included in the WS sample. In the case of Kytalyk, the GM backscatter values are more than $2 \mathrm{~dB}$ lower than in WS. 


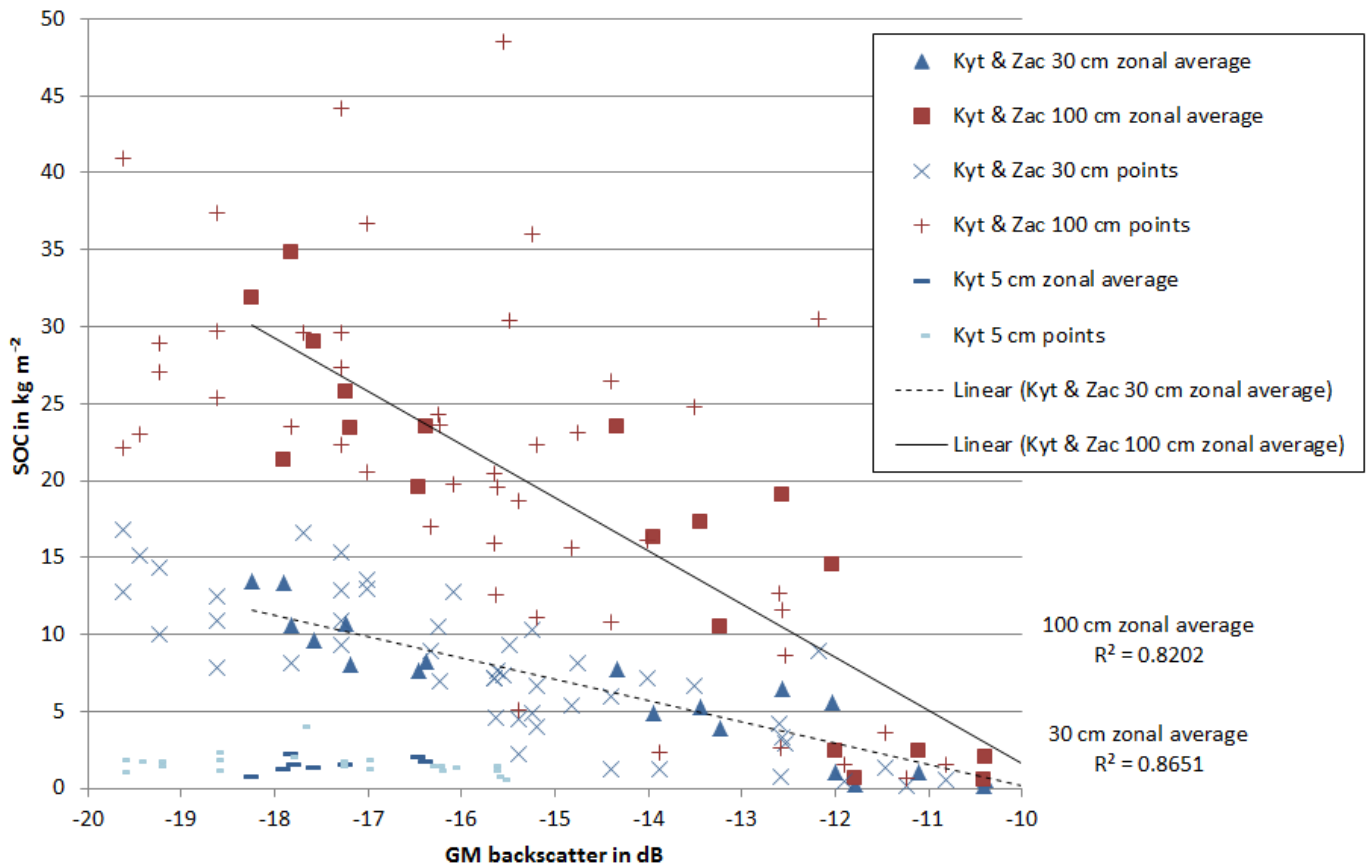

Figure 4. SOC from land cover classifications and pedon data (points) for all depths versus backscatter from ENVISAT ASAR GM, for Kytalik (Kyt) and Zackenberg (Zac). Five-centimetre data are only available for Kytalyk.
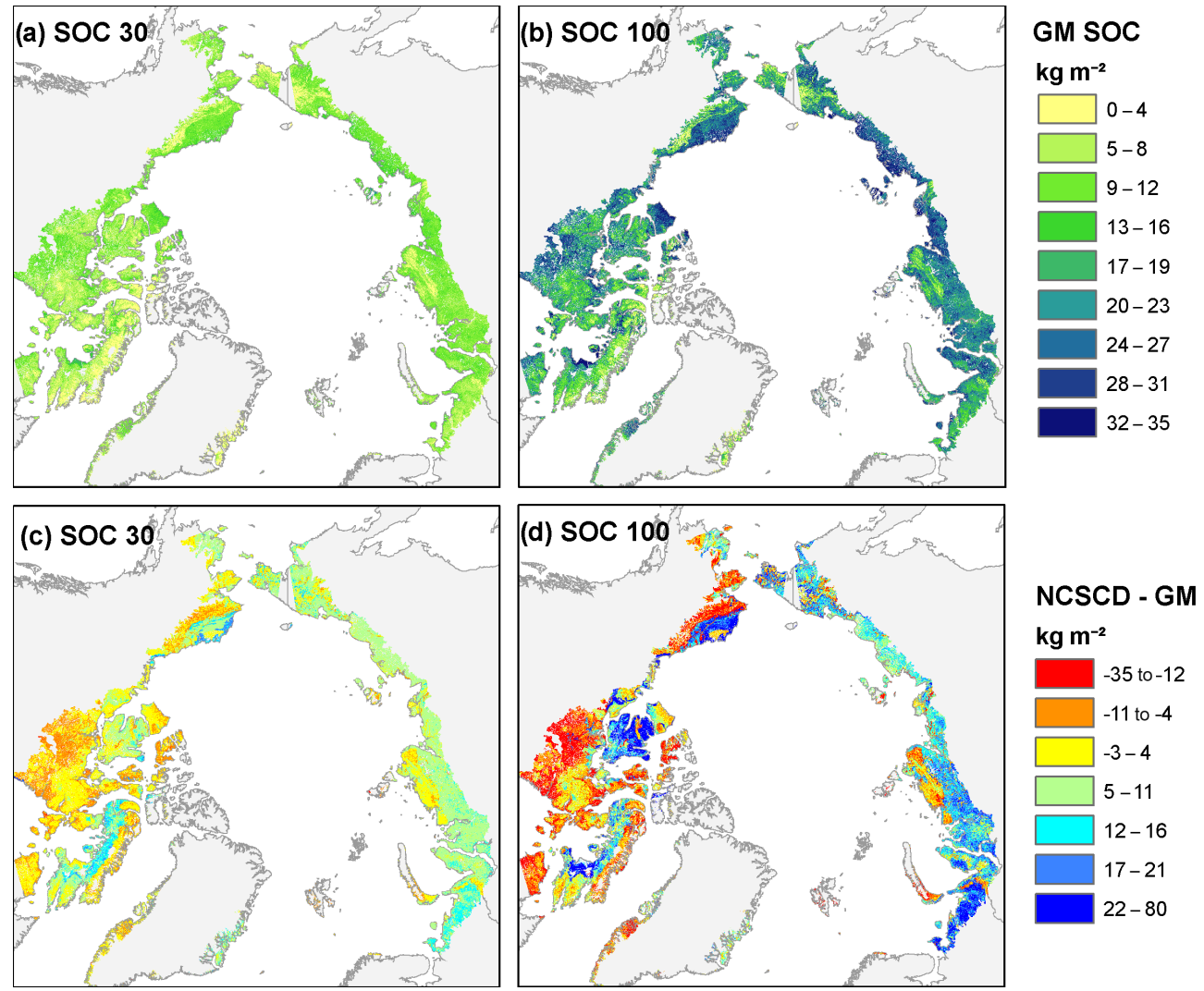

Figure 5. SOC results from ENVISAT ASAR GM (a) 0-30 and (b) 0-100 cm, and SOC difference between NCSCD and ENVISAT ASAR GM (c) $0-30$ and (d) $0-100 \mathrm{~cm}$. 


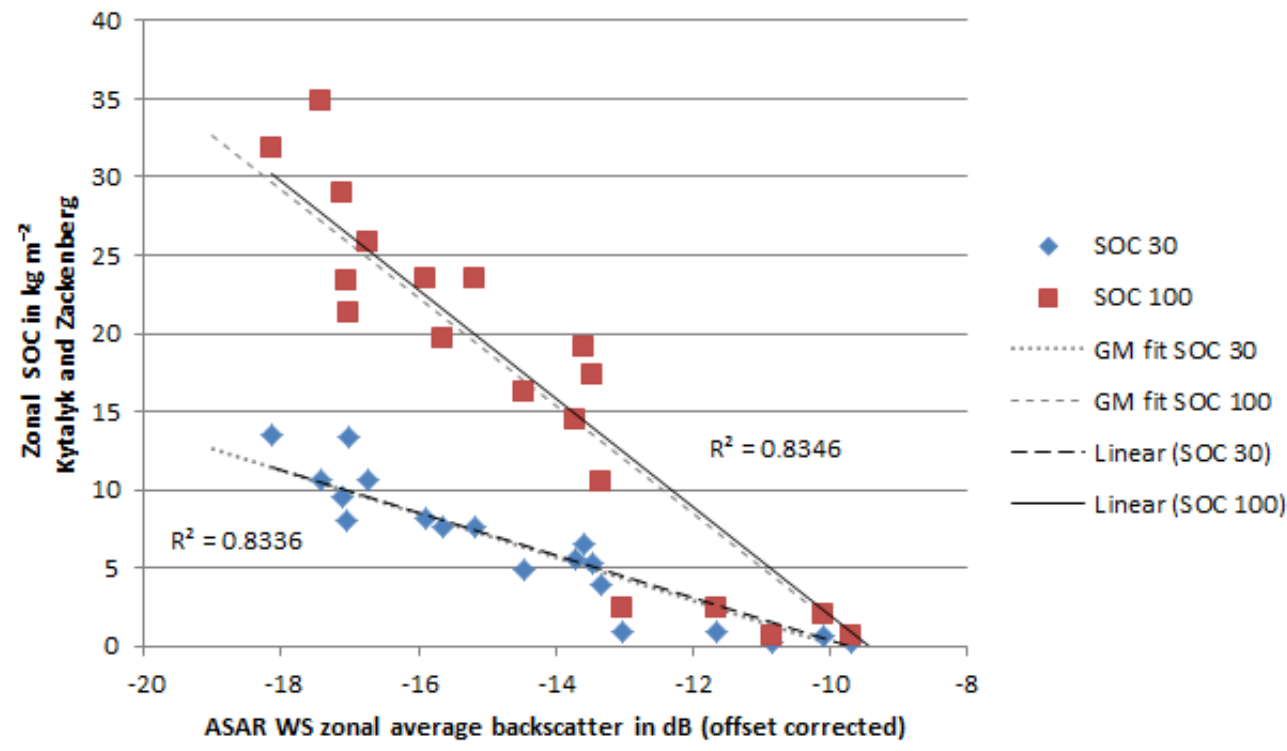

Figure 6. SOC for 30 and $100 \mathrm{~cm}$ depths versus backscatter from ENVISAT ASAR WS (offset corrected) for Kytalyk and Zackenberg including function for linear fit of the GM data (see Fig. 4)

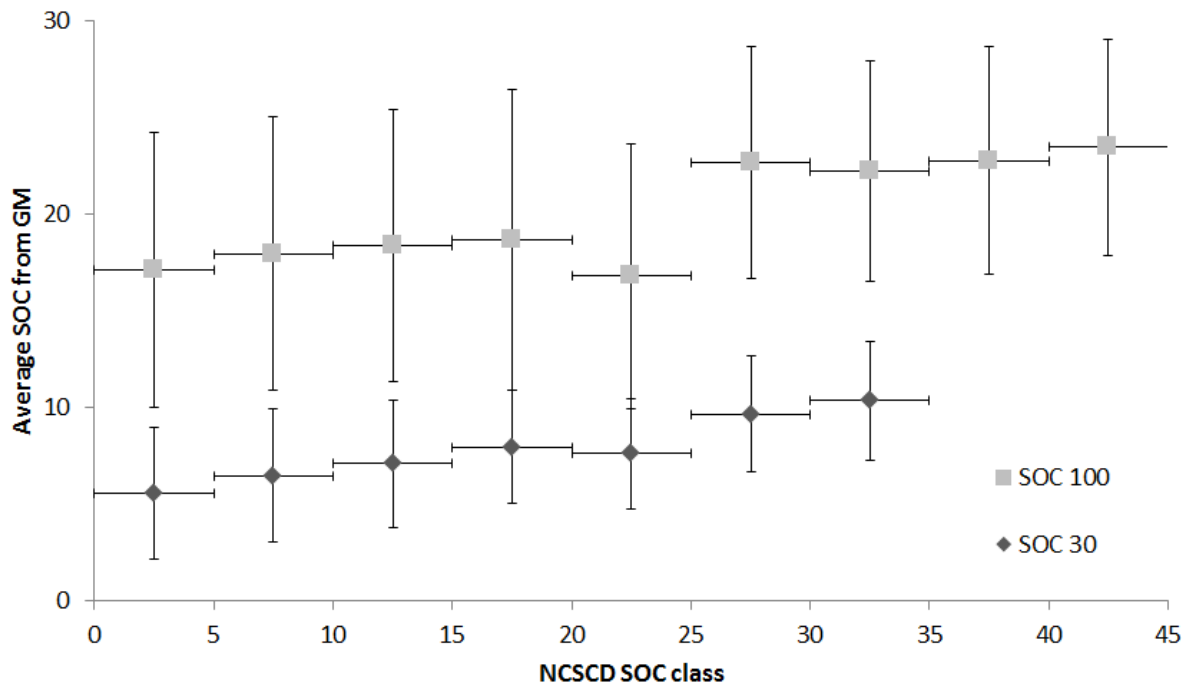

Figure 7. SOC in $\mathrm{kg} \mathrm{m}^{-2}$ from the GM results averaged over a class range of $5 \mathrm{~kg} \mathrm{~m}^{-2}$ in the NCSCD

The root mean square error (RMSE) determined using the Tulemalu and Arymas reference (point) data is $7.67 \mathrm{~kg} \mathrm{~m}^{-2}$ for $0-30 \mathrm{~cm}$ and $17.24 \mathrm{~kg} \mathrm{~m}^{-2}$ for $0-100 \mathrm{~cm}$. If peat bog sites are excluded values are reduced to 3.79 and $7.58 \mathrm{~kg} \mathrm{~m}^{-2}$ respectively. This corresponds to $20-25 \%$ of the range of in situ SOC values. This is in the order of the standard deviation found for SOC values within the specified land cover classes at, for example, Zackenberg (Palmtag et al., 2015). The averages of the GM results $(100 \mathrm{~cm})$ over the validation sites reflect the differences between Shalaurovo and Arymas (Table 2). SOC is lower at the latter site, which agrees with the in situ records.

\subsection{Comparison with independent datasets}

Large negative deviations of more than $10 \mathrm{~kg} \mathrm{~m}^{-2}$ from the high-resolution land cover maps (Table 1) are only found for peat bogs (Fig. 9) which are located at Tulemalu. This is also consistent with the pedon derived information for soil types (Fig. 10). SOC stocks at sites with histels are in most cases underestimated.

The mean difference between the NCSCD and the GM result is 3.8 and $5.8 \mathrm{~kg} \mathrm{~m}^{-2}$ for 30 and $100 \mathrm{~cm}$ respectively (standard deviation of 6.3 and $15.1 \mathrm{~kg} \mathrm{~m}^{-2}$ ). SOC totals within the CAVM domain are listed in Table 3. 


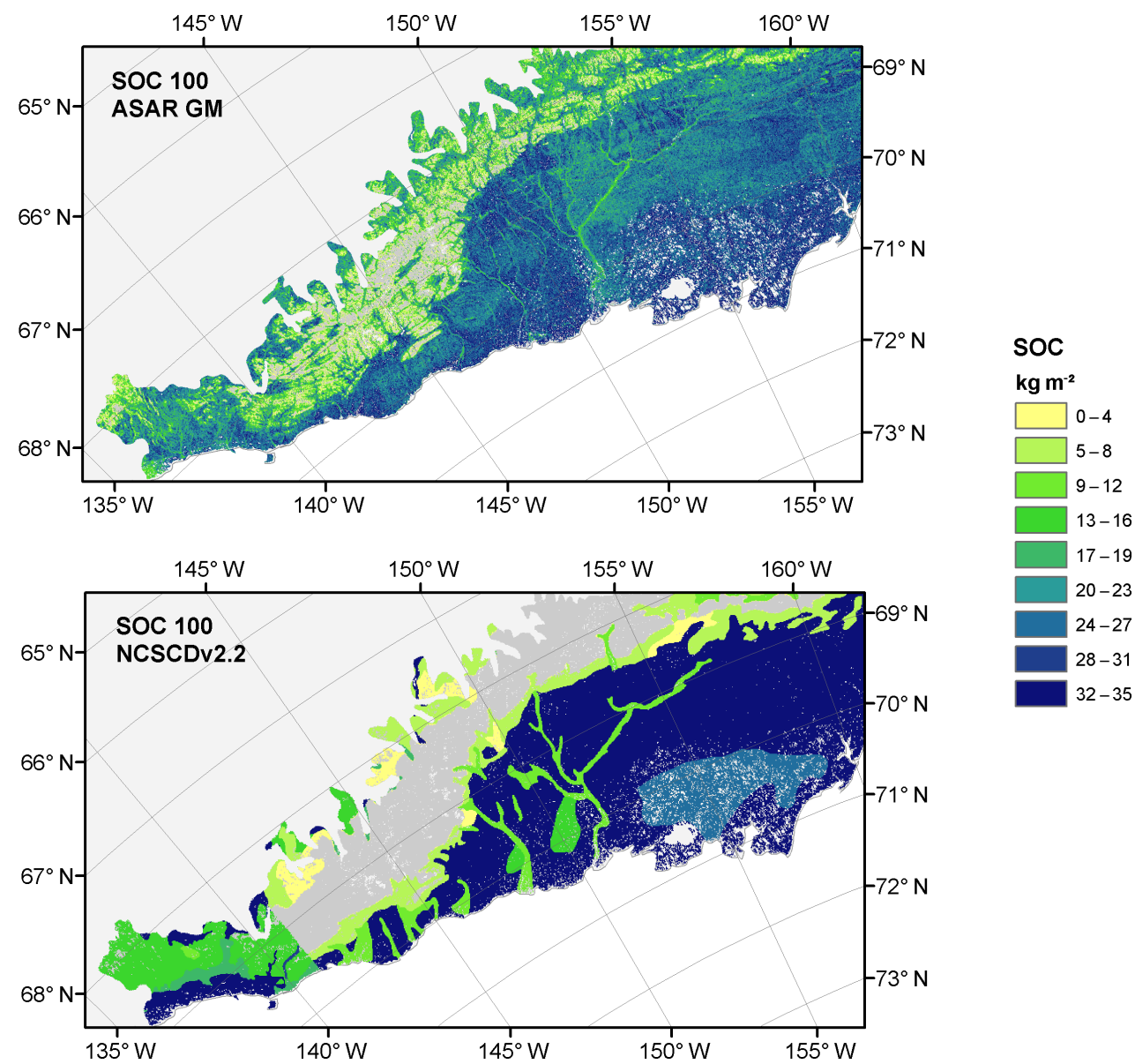

Figure 8. Subset maps (Alaska-Canada border region and parts of the Brooks Range and North Slope) of SOC 0-100 cm results from ENVISAT ASAR GM and the NCSCD. For legend, see Fig. 5a; medium-grey values correspond to $0 \mathrm{~kg} \mathrm{~m}^{-2}$
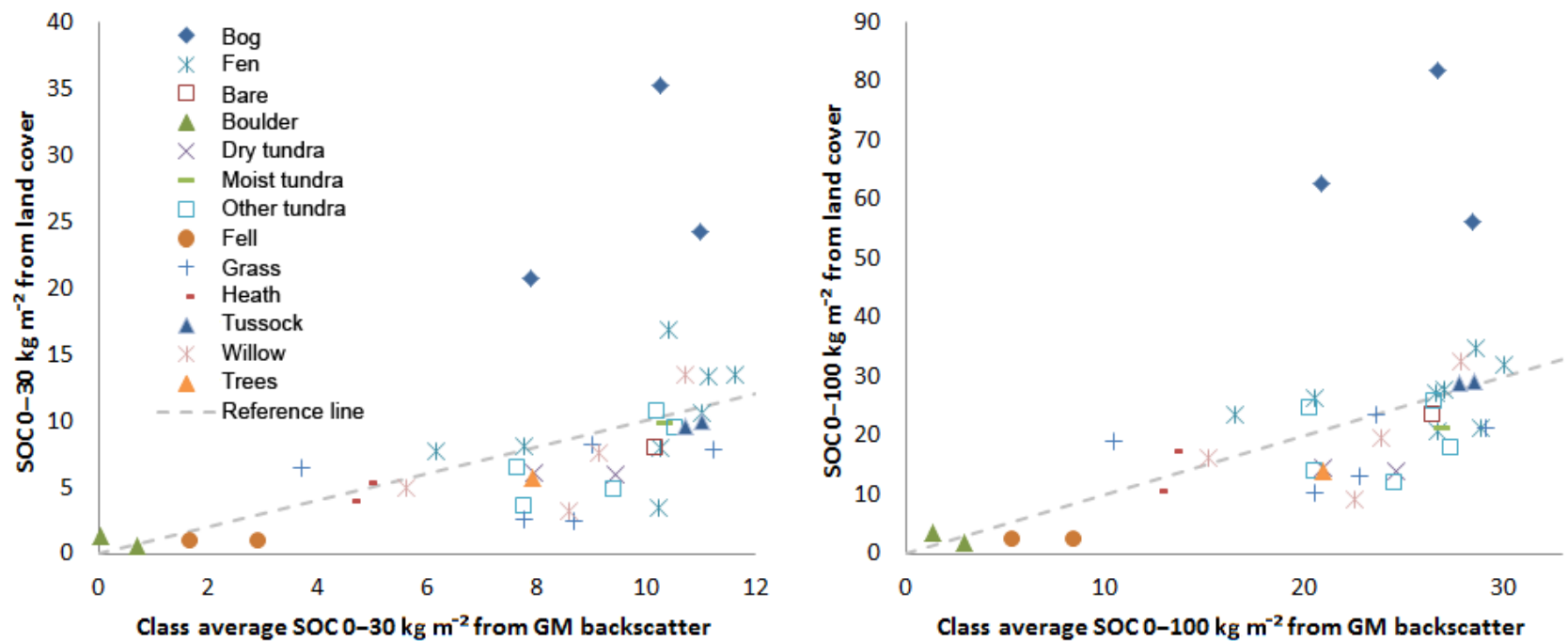

Figure 9. SOC from land cover classifications (all sites: Kytalik, Zackenberg, Tulemalu, Shalaurovo and Arymas) vs. SOC from ENVISAT ASAR GM, by land cover (harmonized classes) and depth: left, 0-30 cm; right, 0-100 cm. 
Table 2. Averaged SOC in $\mathrm{kg} \mathrm{m}^{-2}$ (30 or $100 \mathrm{~cm}$ as indicated) for in situ (pedons - P), remotely sensed (ASAR GM - Global Monitoring mode; WS - Wide Swath mode) and the NCSCD soil data. Only points with available values for pedon as well as ASAR data are used.

\begin{tabular}{lrrrrrrr}
\hline Site name & P 30 & WS 30 & GM 30 & NCSCD 30 & P 100 & GM 100 & NCSCD 100 \\
\hline Kytalyk & 11.2 & 10.9 & 10.5 & 17.6 & 27.4 & 27.4 & 57 \\
Zackenberg & 4.2 & 6.84 & 5.4 & 9.7 & 16.1 & 15 & 17.8 \\
Shalaurovo & 9.6 & - & 10.5 & 17.1 & 26.6 & 27.3 & 38.4 \\
Tulemalu & 13.8 & - & 9.2 & 6.3 & 28.5 & 24.1 & 19 \\
Arymas & 7.8 & - & 8.4 & 11.9 & 18.2 & 22.1 & 18.2 \\
\hline
\end{tabular}

Table 3. Total SOC values (30 and $100 \mathrm{~cm}$ as indicated) derived from the different data sources: LC - land cover; WS - Wide Swath; GM Global Monitoring mode; and NCSCD

\begin{tabular}{lrrrrrrr}
\hline Region & LC 30* & WS 30 & GM 30 & NCSCD 30 & LC 100* & GM 100 & NCSCD 100 \\
\hline Kytalyk (in Tg C) & 0.495 & 0.50 & 0.47 & 0.81 & 1.21 & 1.30 & 2.62 \\
CAVM domain (in Pg C) & - & - & 29.2 & 41.5 & - & 80.6 & 94.0 \\
\hline
\end{tabular}

* Excluding areas with cloud cover, approximately $5 \%$.

The differences increase with increasing SOC in the NCSCD (Fig. 7). SOC values from GM for both 30 and $100 \mathrm{~cm}$ are mostly higher across North America and lower across Siberia (Fig. 5). Transitions between areas of positive and negative value regions are sharp, reflecting boundaries of maps which underlie the NCSCD (Fig. 8). SOC values change at country borders, e.g. between the USA and Canada along $141^{\circ} \mathrm{W}$. Gradients are only to a certain level of detail represented.

The residual plots (Fig. 11) for the depth of organic layer and cryoturbated carbon also confirm that the SAR method is biased low in sites with substantial cryoturbation and deep $\mathrm{O}$ horizons. The SAR method is biased high for sites with limited cryoturbation and/or less than $10 \mathrm{~cm}$ organic layer thickness. The differences do not relate to cryoturbated carbon in the case of $30 \mathrm{~cm}$ estimates $\left(R^{2}=0.14\right)$ but do to some extent for $100 \mathrm{~cm}$ values $\left(R^{2}=0.5\right)$.

The results obtained from the NCSCD for the NDVI classes suggest a bimodal behaviour with the first maximum for NDVI of 0.3, a local minimum for 0.45 and a second maximum for 0.7. The majority of pixels between an NDVI of 0.4 and 0.5 are located within the Canadian Arctic. GMderived SOC is higher than in the NCSCD over large parts of this region, in contrast to what is observed for Siberia.

GM and NCSCD averages for the length of unfrozen period classes (Fig. 10) differ from each other. Maximum SOC in GM corresponds to about 110-120 days of unfrozen period length. A local maximum can be also found for NCSCD over that period, but SOC is higher for more than 150 days.

In the case of the NCSCD as well as the GM records, an increase in SOC with increasing length of the unfrozen period can be shown (Fig. 10). The variability increases for unfrozen period lengths over 120 days due to substantially lower numbers of samples.
SOC over $0-30 \mathrm{~cm}$ for the Kytalyk map extent amounts to $0.5 \mathrm{Tg} \mathrm{C}$ for GM (mean of $10.7 \mathrm{~kg} \mathrm{~m}^{-2}$, standard deviation of 1.7), which agrees with optical data results $(0.495 \mathrm{Tg} \mathrm{C})$. The values obtained from WS data are similar with $0.47 \mathrm{Tg} C$ (mean $9.7 \mathrm{~kg} \mathrm{~m}^{-2}$ ). The standard deviation is higher with $4.4 \mathrm{~kg} \mathrm{~m}^{-2}$. General spatial patterns in the GM and WS maps are similar to the QuickBird-based results (Fig. 12, Table 3). The river floodplain shows lower SOC than the thermokarst landscape to the north. Drained lake basin patterns and associated gradients are still captured with WS but not with GM. These differences are not captured in the NCSCD database. NCSCD SOC $0-30 \mathrm{~cm}$ over the complete area is $17 \mathrm{~kg} \mathrm{~m}^{-2}$, which adds up to $0.81 \mathrm{TgC}$.

The same satellite data source as in this study has been used for discrimination of wetness levels by Widhalm et al. (2015a). Areas with backscatter below $-16.5 \mathrm{~dB}$ have been shown to correspond to wet areas with potentially higher methane emissions. These areas would correspond to SOC $0-100 \mathrm{~cm}$ larger than $25 \mathrm{~kg} \mathrm{~m}^{-2}$. This is confirmed by the fen and moist tundra records from the reference datasets (Table 1, Fig. 9). Medium or mixed wetness corresponds to about $20-25 \mathrm{~kg} \mathrm{~m}^{-2}$. Several willow, grass, fen and dry tundra samples fall into this category. Dry areas as defined in Widhalm et al. (2015a) correspond to mostly fell, heath and boulder classes. The majority of pedon records from histels and non-permafrost mineral soils can also be found in this category (see Fig. 13). Turbels and orthels can be associated with the mixed and wet classes with about $50 \%$ of the turbels and $25 \%$ of the orthels in the wet class based on the pedon data. Orthels also represent about $50 \%$ in the wet class using the GM quantification. 

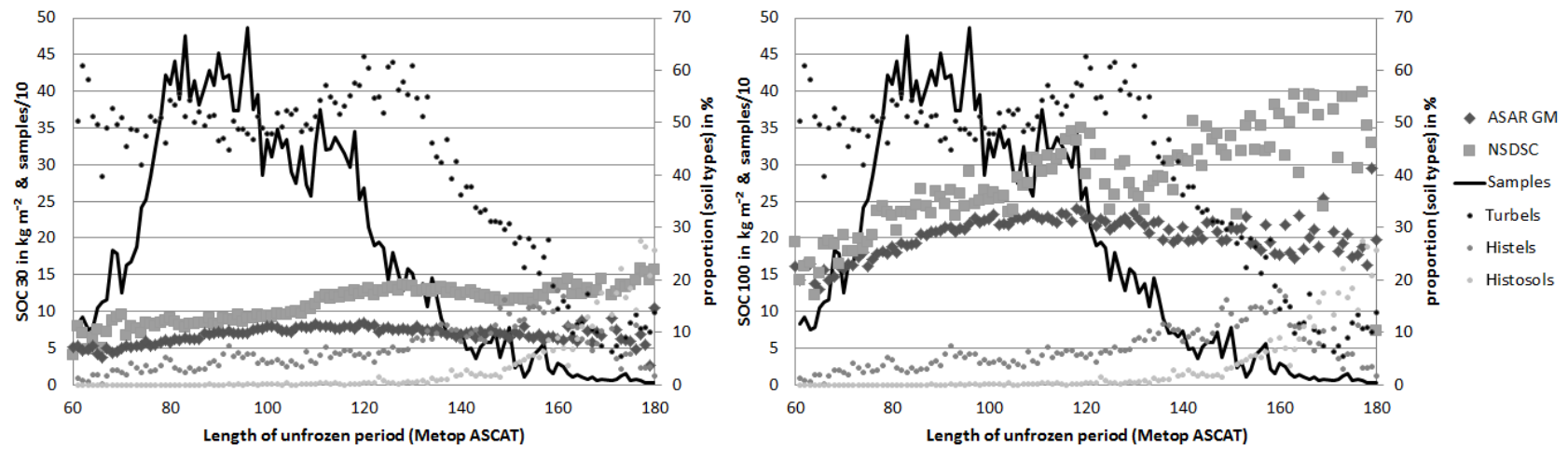

Figure 10. SOC from GM and the NCSCD (including mean \% of turbels, histosols and histels) in comparison to unfrozen period length (source Paulik et al., 2012). Left: 0-100 cm SOC; right: 0-30 cm SOC. Values and soil type \% have been averaged for class increments of 1 day. Samples correspond to pixels of $12.5 \mathrm{~km} \times 12.5 \mathrm{~km}$
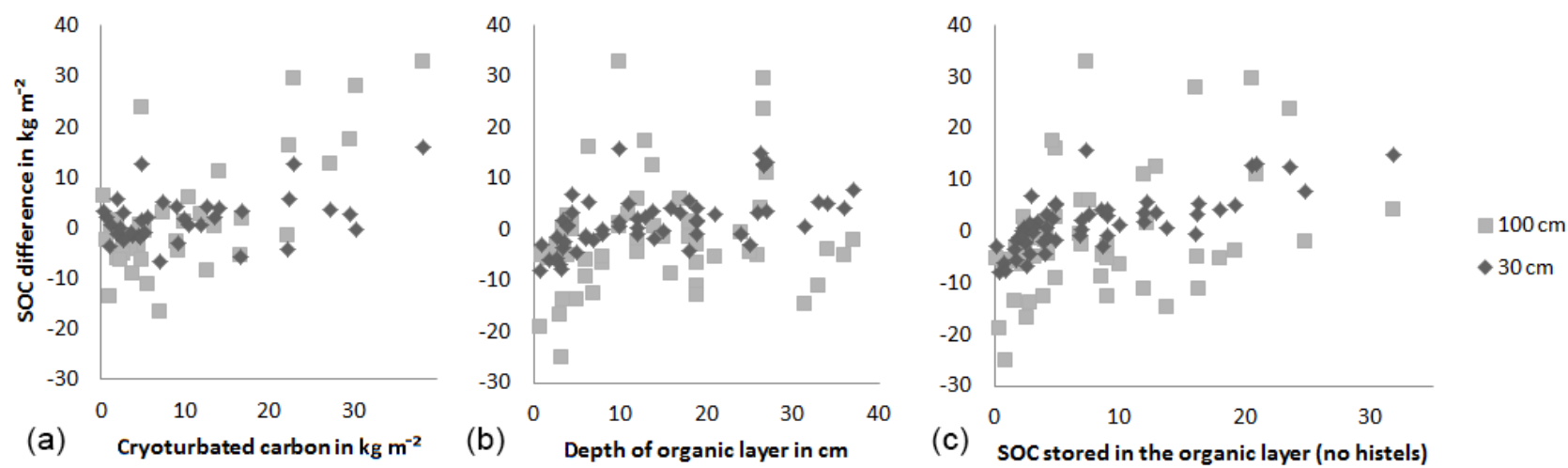

Figure 11. SOC differences between results from ENVISAT ASAR GM and pedon (point) measurements from Kytalyk and Tulemalu in comparison to amount of cryoturbated carbon (left; $R^{2} 0.5$ and 0.14 for 100 and $30 \mathrm{~cm}$ respectively), depth of organic layer (middle; $R^{2} 0.59$ and 0.62 for 100 and $30 \mathrm{~cm}$ respectively) and SOC stored in the organic layer (right; $R^{2} 0.66$ and 0.69 for 100 and $30 \mathrm{~cm}$ respectively).

\section{Discussion}

\subsection{Representativeness of C-band backscatter}

The observed GM backscatter range for frozen conditions of $10 \mathrm{~dB}$ for terrestrial surfaces provides sufficient sensitivity to SOC variations in this landscape type. It is larger than for other common C-band backscatter-based applications. In comparison, freeze-thaw detection algorithms rely on a difference of about $1-3 \mathrm{~dB}$ between frozen and unfrozen conditions (Park et al., 2011). On average, backscatter decreases about $1-1.5 \mathrm{~dB}$ during freeze-up for wetlands compared to dry land cover types with about $0.5 \mathrm{~dB}$ over the CAVM domain (Widhalm et al., 2015a). A differentiation of wetland types (Widhalm et al., 2015a) from December minimum backscatter is based on class ranges starting at only $1.5 \mathrm{~dB}$. Potential backscatter increase due to snow property changes is also lower than the observed range for SOC with about 2-3 dB (Naeimi et al., 2012). Soil moisture variation (dry to saturated) in tundra regions without significant proportion of water bodies causes about $5 \mathrm{~dB}$ variation during summertime (Högström et al., 2014).

The empirically derived function for ASAR GM is also applicable to WS when incidence angle effects are accounted for. The location-specific normalization applied for the GM records to solely December data ensures that the underlying samples represent the same surface type and condition. The number of available WS records is, however, in general lower than for GM in the Arctic and varies spatially and temporally (Bartsch et al., 2012). When just a few images are available, as in most cases for WS, only conventional normalization can be applied. The local multi-annual backscatter minimum of December (derived to reduce impact from a potential unusually large snow depth or ice layers) might be therefore different between WS and GM. GM data are in addition characterized by much larger noise than data acquired in WS mode (Park et al., 2011). This effect is, however, reduced by using the minimum of the 7-year record (Widhalm et al., 2015a). The noise may still contribute to the slightly larger range of values observed in the GM data (Figs. 4 and 6). 


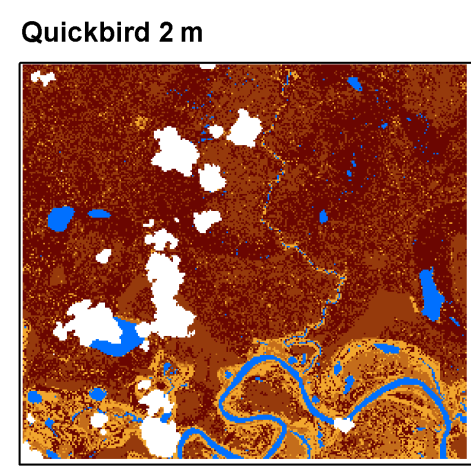

ASAR WS $75 \mathrm{~m}$

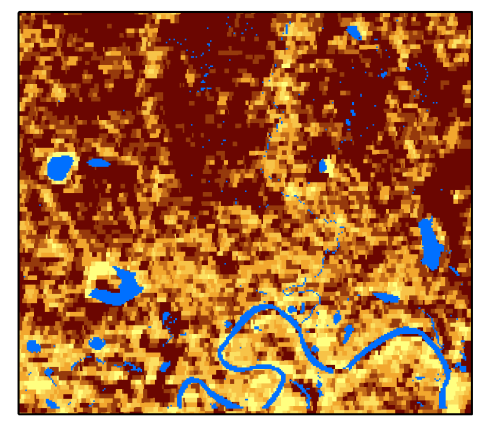

\section{NCSCD}

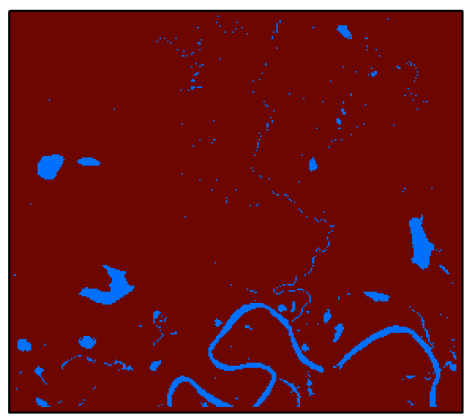

ASAR GM $500 \mathrm{~m}$

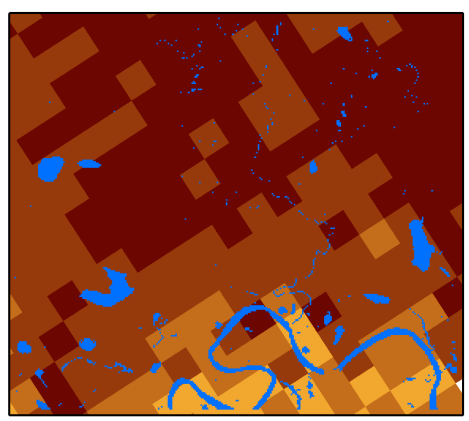

$8 \mathrm{~km}$
SOC $0-30 \mathrm{~cm}$

$\mathrm{kg} \mathrm{m}^{-2}$

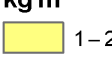

2.01-4

$\square .01-6$

ए $6.01-8$

$8.01-9$

$9.01-11$

$>11$

Figure 12. SOC 0-30 cm from QuickBird (Siewert et al., 2015), NCSCD (Hugelius et al. (2014)), ENVISAT ASAR WS and GM (resampled to a grid with polar stereographic projection) for Kytalyk. Water bodies and clouds from QuickBird classification are shown in blue and white respectively. NCSCD contains a constant value of $17 \mathrm{~kg} \mathrm{~m}^{-2}$ across the area.

The foreshortening effects that are typical for SAR acquisitions would need to be accounted for when this method is applied in mountain areas, especially for WS data. An application of the approach to WS over larger areas would also require appropriate normalization in order to account for incidence angle effects. In addition, the utilization of the effect of incidence angle on sensitivity to roughness effects (Baghdadi et al., 2001) could be exploited. The currently operating Sentinel-1 satellite, which is a follow-on mission of ENVISAT ASAR, also acquires data in $\mathrm{C}$ band. The polarizations vary (VV and VH are common). For this study, only $\mathrm{HH}$ was available. The sensitivity to SOC may differ for other polarizations and thus impact the transferability of this approach to, for example, Sentinel-1.

In cases where the near-surface soil is close to saturation during summer, $\mathrm{C}$ band can be used to distinguish peatlands to some extent (Bartsch et al., 2009; Reschke et al., 2012). However, this only leads to a yes/no classification. Such maps (or any other appropriate land cover classification) could be used in addition to the presented approach in order to indicate areas where it is expected that SOC is underestimated.

The correlation with winter backscatter is expected to result from a combination of roughness (surface response) and volume scattering within the remains of the vegetation (re- garding snow; see below). In order to distinguish the different scattering types, polarimetric SAR data as used, for example, in Ullmann et al. (2014) would be required. Such data are, however, not available from ENVISAT ASAR GM. Since winter data are used, only interaction with the remaining woody parts is expected. The contribution from volume scattering from woody vegetation becomes important when stems reach a certain size with respect to the wavelength used. The training and validation sites used also include willow-dominated land cover. The obtained results from these locations do not indicate that the chosen approach is not applicable. SOC derived from ASAR GM is close to SOC from high-resolution optical data (Fig. 7) for willow classes. SOC might, however, be underestimated in the case of thicker stems (more than $5 \mathrm{~cm}$ ).

$\mathrm{L}$ band (approximately $23 \mathrm{~cm}$ wavelength) is expected to penetrate better into the ground in the tundra-taiga transition zone, and it may in general give better indications of soil moisture during the summer season. The interaction with the surface material (roughness and volume scattering) is, however, expected to be much lower than with $\mathrm{C}$ band with respect to the tundra surface characteristics (see Fig. 2). The sensitivity to the relevant surface features which are used as a proxy for SOC is expected to be lower at $\mathrm{L}$ band. 

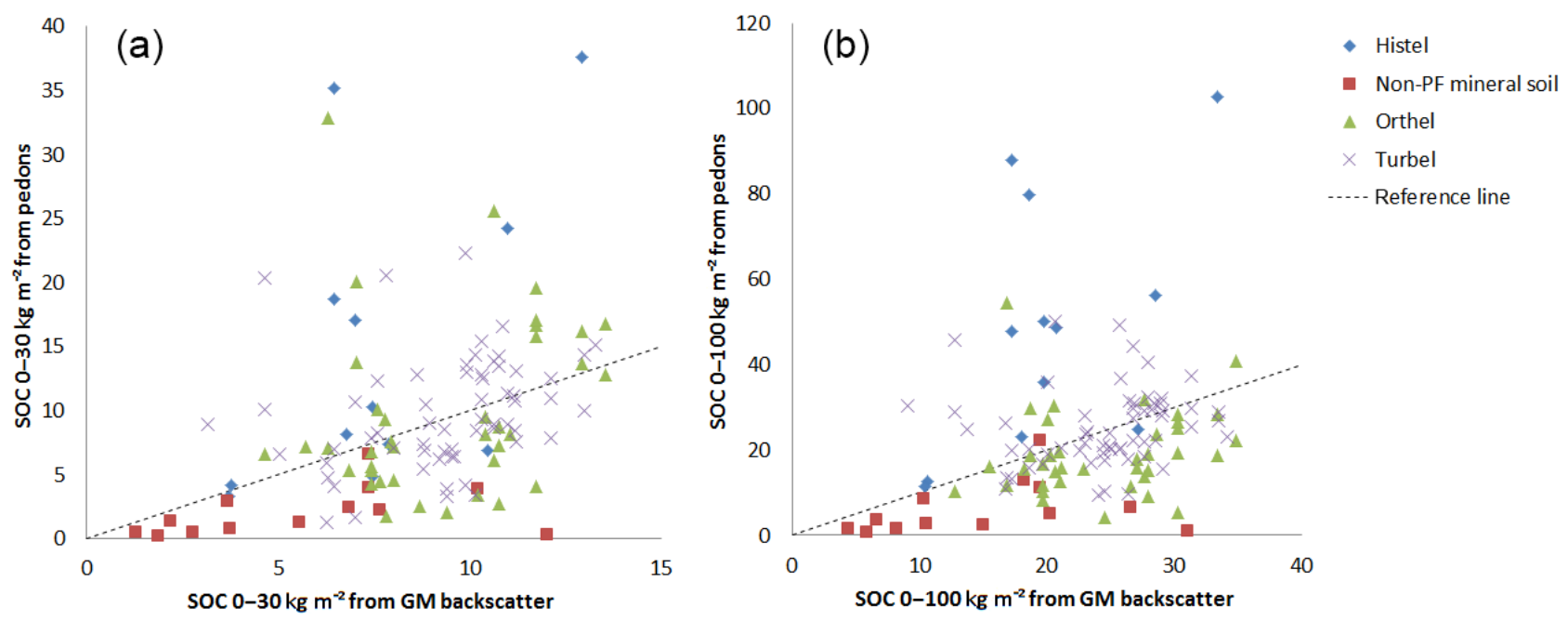

Figure 13. SOC 0-30 (left) and 0-100 cm (right) results from ENVISAT ASAR GM in comparison to pedon (point) measurements from Kytalyk, Zackenberg, Shalaurovo, Arymas and Tulemalu by soil type.
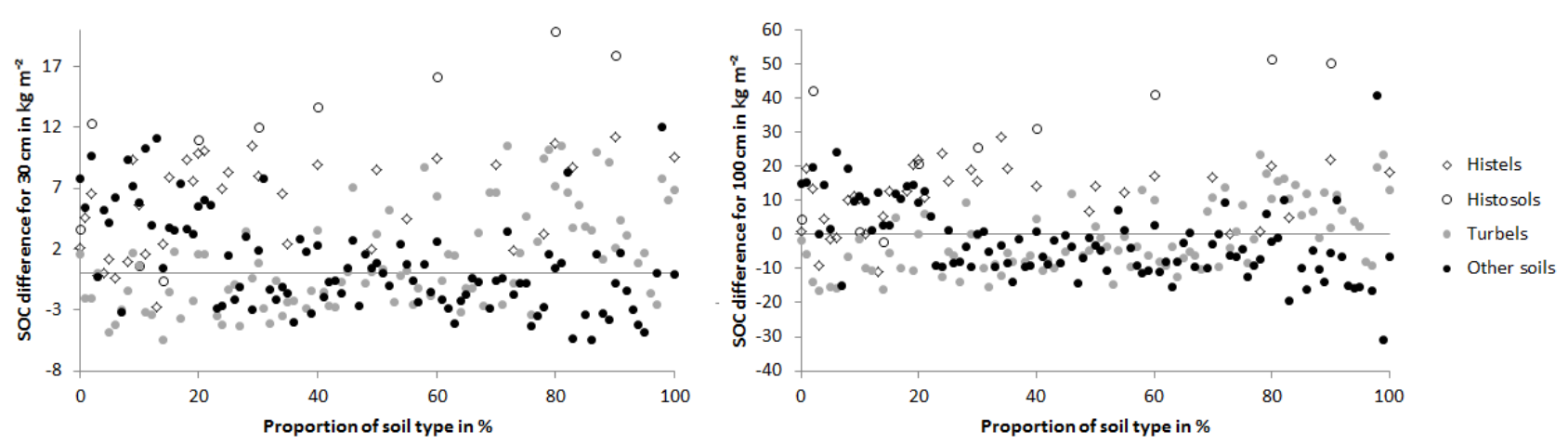

Figure 14. Averaged differences of SOC in $\mathrm{kg} \mathrm{m}^{-2}$ between NCSCD and GM by soil type (averaging intervals $1 \%$; source: NCSCD).

\subsection{Evaluation results}

The large difference (about half of the values in the NCSCD) in SOC observed between the upscaled maps (from both optical and radar data, Fig. 12) at Kytalyk is similar to the NCSCD-GM differences throughout the entire Arctic (Fig. 7). Such a deviation is, however, not found when GM is compared to pedon data across all sites (Fig. 9). NCSCD values are also considerably higher than in situ records for the Siberian sites (Table 2).

The difference between deviations of SOC estimates from the NCSCD for both 30 and $100 \mathrm{~cm}$ between the Siberian and North American part can be to some extent explained by the presence of peatlands. The SAR approach underestimates SOC for histels as well as histosols (Fig. 14). Similarly, SOC from the GM datasets is lower when the proportion of turbels exceeds $20 \%$. This applies to the $30 \mathrm{~cm}$ as well as $100 \mathrm{~cm}$ results. Large parts of the Canadian Arctic as well as the Brooks Range in Alaska have, however, higher SOC in the GM results than in the NCSCD. This might be due to incon- sistencies in the underlying maps. For example, most of the Alaskan Brooks Range has a value of zero SOC (Fig. 8).

Deviations from the land cover based SOC data (Fig. 9) could be also partially due to the limited availability of the reference dataset (Table 1). The included data represent only a small area within the high-resolution satellite data classifications of several-kilometre extent. The available evaluation datasets (Tulemalu and Arymas) do not provide the full range of possible SOC values over areas which are large enough to be detected with the spatial resolution of the SAR data. Validation data only represent SOC values above $10 \mathrm{~kg} \mathrm{~m}^{-2}$ over $100 \mathrm{~cm}$. Only medium to high SOC values are thus used for the determination of the RMSE. A larger range may lead to a reduction in the RMSE.

The larger standard deviation in the WS-derived SOC stocks compared to GM for Kytalyk is expected due to its higher spatial resolution. This reflects the complexity of the landscape at Kytalyk (Siewert et al., 2015). Future studies should consider measures of variation within the SAR resolution cell when using coarse data such as ASAR GM or 


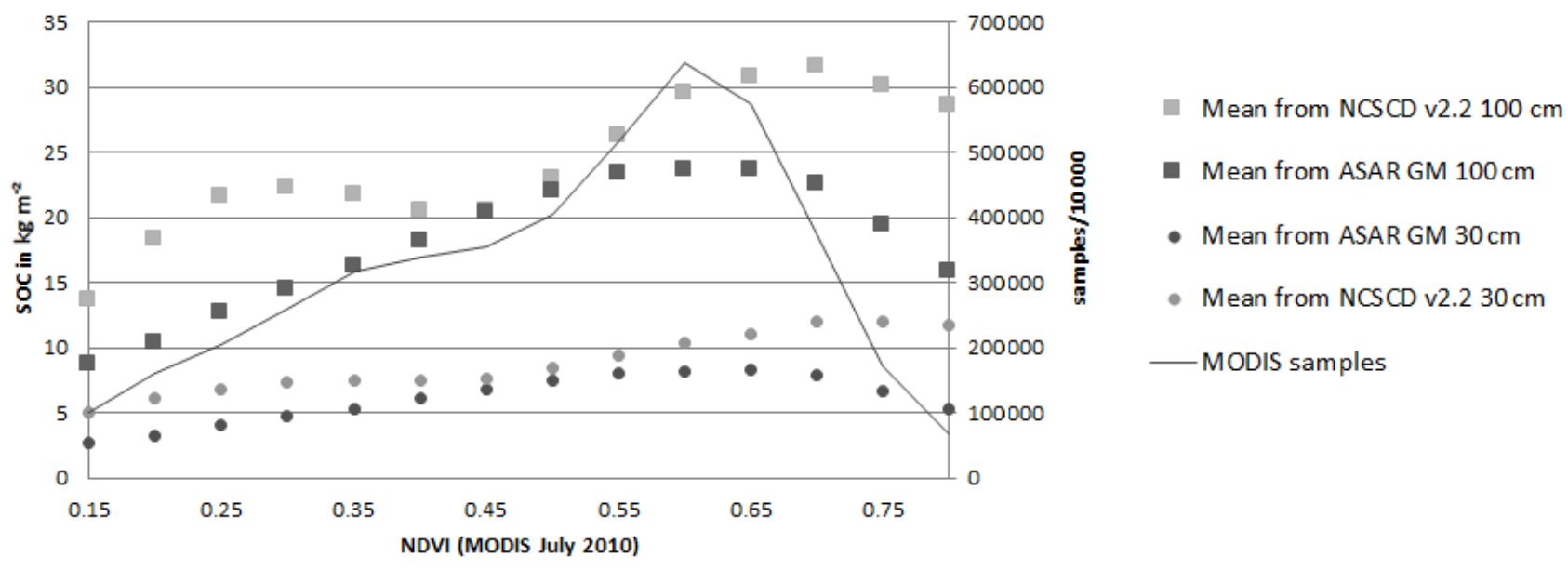

Figure 15. SOC from the GM results as well as the NCSCD in comparison to normalized difference vegetation index (NDVI; source: MODIS). SOC values have been averaged for class increments of 0.05 NDVI

make use of higher-resolution SAR as demonstrated applicable for WS.

The high coefficient of determination for $30 \mathrm{~cm}$ as well as $100 \mathrm{~cm}$ implies that a relationship exists between SOC accounted for over these horizons. This agrees with the NCSCD. Based on linear correlation of the NCSCD version 2.2 pedon database $(n=523, p<0.001, \log$ transformation of data; Hugelius et al., 2013) the $R$ between 30 and $100 \mathrm{~cm}$ SOC stocks is 0.78 . The applied linear relationship between backscatter and SOC is not valid for high-carbon areas such as peat soils. Surface properties as seen by C-band SAR do not change for SOC $0-100 \mathrm{~cm}$ values higher than approximately $35 \mathrm{~kg} \mathrm{~m}^{-2}$. Peat deposits can have similar surface properties but variable depths. Peat accumulation is related to age, and the accumulation rates decrease exponentially in thermokarst basins (Jones et al., 2012).

SOC values are also underestimated in areas with extensive cryoturbation, e.g. in North America (like northern Alaska and the coast of the Canadian Archipelago, Fig. 5c and d). Soil types are not reflected in the reference maps (Table 1) but are in the original pedon data. A comparison with the in situ records shows that SOC is underestimated in most cases for histels (Fig. 13), which are equivalent to permafrost peatlands ( $>40 \mathrm{~cm}$ O horizon). Turbels (in this study defined as permafrost soils with more than $1 \mathrm{~kg}$ cryoturbated carbon) are also underestimated in some cases. This can be clearly observed for SOC over $100 \mathrm{~cm}$. The process of cryoturbation may lead to a roughening of the surface and thus ambiguities with characteristics typical for lower SOC content soil types.

SOC of non-permafrost mineral soils and orthels (mineral permafrost soil without cryoturbation) is mostly overestimated, although the assumption that carbon content increases with decreasing backscatter seems to be valid. This could be due to the inclusion of areas with cryoturbated soils into the training dataset. Turbels are typical at Kytalyk. Furthermore, the occurrence of mixed pixels may contribute to this over- estimation. Non-permafrost mineral soils are often found at river banks and the area they cover is smaller than the resolution of ASAR GM data. Backscatter within such a GM pixel would be lower in the case of grounded ice within that cell. This is partially possible for shallow river sections. There is interaction of microwaves at the water-ice boundary of floating ice. If ice on water bodies is freezing to the ground, the backscatter mechanisms change and the backscatter intensity recorded at the sensor drops significantly (e.g. Jeffries et al., 1993). This has an effect on SOC retrieval in the case of pixels which include very shallow water which freezes to the bed as early as in the beginning of winter, thus resulting in higher SOC estimates. A value of more than $30 \mathrm{~kg} \mathrm{~m}^{-2}$ over $100 \mathrm{~cm}$ is, for example, derived from GM for a pedon with $1 \mathrm{~kg} \mathrm{~m}^{-2}$ from Arymas which represents a sandbar. A water surface map with higher spatial resolution than the SAR data used would be required in order to mask out affected pixels.

The land cover types of the reference maps (Table 1) can be associated with a certain SOC range (Fig. 13), which supports the chosen upscaling approaches of Siewert et al. (2015) and Palmtag et al. (2015). However, only boulder areas, fells, heath, dry tundra and tussock sites are distinct and with a low range of values. Fen, willow and grass classes require further separation into subclasses to represent their SOC value range. This needs to be considered when landscape-based upscaling is pursued from land cover maps.

The average amount of carbon across the CAVM domain of $19.6 \mathrm{~kg} \mathrm{~m}^{-2}$ over $100 \mathrm{~cm}$ is lower than the estimate of $34 \mathrm{~kg} \mathrm{~m}^{-2}$ by Ping et al. (2008) over the North American part. This could be attributed to the presence of peatlands and deeply cryoturbated soils in this region. The carbon stock total by Ping et al. (2008) is, however, 98.2 Pg C for North America alone, which is higher than the circumpolar account from the NCSCD (94 Pg C). Mishra and Riley (2012) obtained an RMSE of $17.8 \mathrm{~kg} \mathrm{~m}^{-2}$ for the active layer in Alaska using environmental parameters including topography and 
temperature. Active layer ranges from 14 to $93 \mathrm{~cm}$ according to Mishra and Riley (2014). This RMSE is in the same order of magnitude as for the C-band approach (RMSE of $17.24 \mathrm{~kg} \mathrm{~m}^{-2}$ over $\left.100 \mathrm{~cm}\right)$.

\subsection{Potential and limitations of the C-band approach}

The conclusion of Horwath Burnham and Sletten (2010) that NDVI might be only applicable for upscaling in the high Arctic is confirmed when GM SOC values are compared to NDVI (MODIS July 2010, Fig. 15). SOC increases with NDVI, but decreases when a certain level is reached. This differs between the GM and NCSCD values. In the case of GM, values increase linearly until NDVI values of 0.6. They decrease for higher NDVI values. As SOC increases with decreasing backscatter, the same can be assumed for low to medium NDVI. A linear relationship between $\mathrm{C}$ band backscatter at $\mathrm{HH}$ polarization and NDVI has also been found by Wang et al. (2013) for values higher than 0.6 for subtropical regions. They report increasing NDVI with increasing backscatter, which agrees with our findings. As described above, C-band backscatter relates to higher woody vegetation in areas south of the tree line. Winter backscatter spatial variability in forested regions represents growing stock volume (Santoro et al., 2011). This is reflected in the NDVI as well as unfrozen period comparisons.

GM-derived SOC indicates a maximum of SOC production in areas where there is reasonable plant productivity and litter input and continuous permafrost-promoting soil cryoturbation. This corresponds to an unfrozen period length less than approximately 110-120 days. NCSCD as well as GM SOC values increase with in increasing unfrozen period length below that length. Both calibration sites (Kytalyk and Zackenberg) fall into that zone of similar behaviour. This suggests an applicability of the GM approach to areas with up to 4 months of unfrozen conditions. An increase in SOC with mean annual air temperature until a certain threshold, followed by an inverted relationship similar to that found for the comparison of ASAR GM-derived SOC and the length of unfrozen period, has been reported by Mishra and Riley (2012) for Alaska.

The local SOC minimum in the NCSCD around an unfrozen period length of 130 days corresponds to western Alaska and western Russia. The peak and high differences in SOC between the datasets at around 120 days also correspond to the maximum in turbel occurrence. This confirms the limitation of the approach in areas with intensive cryoturbation as obtained from comparison with the in situ records (Fig. 13).

The wetland (wetness level) classification by Widhalm et al. (2015a), which is based on the same principle (December minimum $\mathrm{C}$-band backscatter), can also be interpreted for carbon levels. High-SOC areas coincide with high wetness (Weiss et al., 2016). Conventional approaches for nearsurface saturation determination based on C-band data utilize unfrozen period data only (e.g. Wagner et al., 1999). This does, however, require a location-specific calibration and at least one dense record of one summer season to identify high SOC areas (Reschke et al., 2012). A consistent coverage is, however, not available for SAR data. The sensitivity to saturation levels also varies by vegetation coverage (Pathe et al., 2009). Such approaches furthermore rely on the assumption that roughness and scatting mechanisms do not change over time, which is not the case over many areas in the high latitudes (Högström et al., 2014). C-band winter backscatter can be shown to be used as an alternative, as a proxy for wetness levels as well as soil organic carbon storage.

At the panarctic scale the method and dataset created currently provides in the first place a means to assess the consistency of maps from conventional sources (soil maps). In order to produce a reliable panarctic map which fully accounts for peat, combination with other sources (e.g. NCSCD) is required. To use the current version, areas with high SOC content (e.g. $>35 \mathrm{~kg} \mathrm{~m}^{-2}$ for $100 \mathrm{~cm}$ ) should be masked (replaced with other estimates if available). For future studies, we propose in addition a fusion with other land cover information (especially peatland extent from remotely sensed data) to spatially confine the high SOC area better. This requires a reliable circumpolar peatland map, which is currently not available.

\section{Conclusions}

Upper limits of the applicability of the C-band SAR approach are approximately 0.6 NDVI and about 120 days of unfrozen surface conditions. Near-surface soil organic carbon can be quantified with C-band SAR data for Arctic and subarctic environments for non-peatlands and soils with limited cryoturbation. Results suggest that in total $>29 \mathrm{PgC}$ soil organic carbon is stored in the upper $30 \mathrm{~cm}$ north of the tree line (CAVM domain). The ENVISAT ASAR GM circumpolar estimates for SOC are about $25 \%$ lower than the NCSCD account (including peatlands). This underestimation differs between regions and points to inconsistencies in the NCSCD. The spatial continuity of our approach allows the quantification of sparsely vegetated areas that are mapped as $0 \mathrm{~kg} \mathrm{~m}^{-2}$ in the NCSCD, as exemplified for the Brooks Range in Alaska. The estimates of total SOC stored in the upper soil layer is similar for the different investigated sources (land-cover-based estimate and C-band backscatter from satellite data) and across scales (different C-band resolutions) for the Kytalyk test site. The results from ASAR GM as well as in situ records suggest that NCSCD estimates for the Siberian tundra area are too high.

Carbon-rich soils ( $>35 \mathrm{~kg} \mathrm{~m}^{-2}$ over $100 \mathrm{~cm}$ ) cannot be captured with this approach. Soil processes such as cryoturbation may in addition lead to increased surface roughness and therefore underestimation of SOC when using the SAR approach. A fusion of traditional land cover information and 
backscatter (frozen ground and low snow cover as used in this study) may provide a means to produce spatially consistent circumpolar estimates including peat soils. The length of unfrozen period in addition to the normalized difference vegetation index are circumarctic-available products that might be suitable supporting variables for modelling the spatial distribution of soil organic carbon.

\section{Data availability}

The circumpolar SOC retrievals are available at https://doi. org/10.1594/PANGAEA.864712 (Bartsch et al., 2016). The dataset contains four layers: SOC 0-30 cm; SOC 0-100 cm; first quality flag - value 1 for potential area of underestimation; and second quality flag - value 1 for potential area of overestimation (based on class "other" from Widhalm et al., 2015b).

Author contributions. Annett Bartsch developed the initial concept for the study, performed all analyses on the preprocessed datasets and drafted the manuscript. Barbara Widhalm performed all preprocessing of the satellite data. Peter Kuhry, Gustaf Hugelius, Juri Palmtag and Matthias Siewert collected the in situ data and prepared them for this analysis. All co-authors contributed to concept development and writing of the manuscript, including discussion.

Acknowledgements. Financial support by the European Commission (FP7-ENV-2011, grant agreement no. 282700) through the project Changing Permafrost in the Arctic and its Global Effects in the 21st Century (PAGE21) is gratefully acknowledged. In situ data sharing was made possible through the same project. The Kytalyk soil organic carbon inventory was conducted with support of the above-mentioned EU PAGE21 project; Arymas and Shalaurovo soil sampling and analyses were possible through the financial support provided by the VR ESF CryoCarb project; the Tulemalu fieldwork and subsequent SOC analysis were supported through the EU GLIMPSE project (contract EVK2-2001-00337) and the Swedish Research Council (VR); and the Zackenberg soil organic carbon inventory was made possible through support of the Norden Permanor and Nordforsk DEFROST projects.

Edited by: K. Thonicke

Reviewed by: two anonymous referees

\section{References}

Baghdadi, N., King, C., Bourguignon, A., and Remond, A.: Potential of ERS and RADARSAT data for surface roughness monitoring over bare agricultural fields: application to catchments in Northern France, Int. J. Remote Sens., 23, 3427-3442, 2001.

Bartsch, A.: Monitoring of Terrestrial Hydrology at High Latitudes with Scatterometer Data, in: Geoscience and Remote Sensing, New Achievements, edited by: Imperatore, P. and Riccio, D., Intechweb, Vokuvar, 247-262, 2010.
Bartsch, A., Kidd, R., Pathe, C., Wagner, W., and Scipal, K.: Satellite Radar Imagery for Monitoring Inland Wetlands in Boreal and Sub-Arctic Environments, Journal of Aquatic Conservation: Marine and Freshwater Ecosystems, 17, 305-317, 2007.

Bartsch, A., Wagner, W., Scipal, K., Pathe, C., Sabel, D., and Wolski, P.: Global Monitoring of Wetlands - the Value of ENVISAT ASAR Global Mode, J. Environ. Manag., 90, 2226-2233, 2009.

Bartsch, A., A.Trofaier, Hayman, G., Sabel, D., Schlaffer, S., Clark, D., and Blyth, E.: Detection of Open Water Dynamics with ENVISAT ASAR in Support of Land Surface Modelling at High Latitudes, Biogeosciences, 9, 703-714, doi:10.5194/bg-9-7032012, 2012.

Bartsch, A., Widhalm, B., Kuhry, P., Hugelius, G., Palmtag, J., and Siewert, M.: Can C-Band SAR be used to estimate soil organic carbon storage in tundra?, Biogeosciences Discuss., doi:10.5194/bg-2016-157, in review, 2016 (data available at: doi:10.1594/PANGAEA.864712).

Bicheron, P., Defourny, P., Brockmann, C., Schouten, L., Vancutsem, C., Huc, M., and Bontemps, S.: GlobCover: Products Description and Validation Report, Tech. Rep., MEDIASFrance, Toulouse, 2008.

Brown, S. C. M., Quegan, S., Morrison, K., Bennett, J. C., and Cookmartin, G.: High-resolution measurements of scattering in wheat canopies? Implications for crop parameter retrieval, IEEE Trans. Geosci. Remote Sens., 41, 1602-1610, 2003.

Closa, J., Rosich, B., and Monti-Guarnieri, A.: The ASAR Wide Swath Mode Products, in: IEEE International Geoscience and Remote Sensing Symposium 2003, IEEE, 2, 1118-1120, 2003.

Duguay, Y., Bernier, M., Lévesque, E., and Tremblay, B.: Potential of C and X Band SAR for Shrub Growth Monitoring in SubArctic Environments, Remote Sens., 7, 9410-9430, 2015.

ESA: ENVISAT ASAR Product Handbook, European Space Agency, 2004.

Högström, E. and Bartsch, A.: Impact of backscatter variations over water bodies on coarse scale radar retrieved soil moisture and the potential of correcting with meteorological data, IEEE Trans. Geosci. Remote Sens., accepted, 2016.

Högström, E., Trofaier, A. M., Gouttevin, I., and Bartsch, A.: Assessing Seasonal Backscatter Variations with Respect to Uncertainties in Soil Moisture Retrieval in Siberian Tundra Regions, Remote Sens., 6, 8718-8738, 2014.

Holah, N., Baghdadi, N., Zribi, M., Bruand, A., and King, C.: Potentiel of ASAR/ENVISAT for the caracterisation of soil surface parameters over bare agricultural fields, Remote Sens. Environ., 96, 78-86, 2005.

Horwath Burnham, J. and Sletten, R. S.: Spatial distribution of soil organic carbon in northwest Greenland and underestimates of High Arctic carbon stores, Global Biogeochem. Cy., 24, GB3012, doi:10.1029/2009GB003660, 2010.

Hugelius, G.: Spatial upscaling using thematic maps: An analysis of uncertainties in permafrost soil carbon estimates, Global Biogeochem. Cy., 26, GB2026, doi:10.1029/2011gb004154, 2012.

Hugelius, G., Kuhry, P., Tarnocai, C., and Virtanen, T.: Soil organic carbon pools in a periglacial landscape: a case study from the central Canadian Arctic, Permafrost Periglac., 21, 16-29, doi:10.1002/ppp.677, 2010.

Hugelius, G., Virtanen, T., Kaverin, D., Pastukhov, A., Rivkin, F., Marchenko, S., Romanovsky, V., and Kuhry, P.: High-resolution mapping of ecosystem carbon storage and potential effects of 
permafrost thaw in periglacial terrain, European Russian Arctic, J. Geophys. Res., 116, G03024, doi:10.1029/2010JG001606, 2011.

Hugelius, G., Tarnocai, C., Broll, G., Canadell, J. G., Kuhry, P., and Swanson, D. K.: The Northern Circumpolar Soil Carbon Database: spatially distributed datasets of soil coverage and soil carbon storage in the northern permafrost regions, Earth Syst. Sci. Data, 5, 3-13, doi:10.5194/essd-5-3-2013, 2013.

Hugelius, G., Strauss, J., Zubrzycki, S., Harden, J. W., Schuur, E. A. G., Ping, C.-L., Schirrmeister, L., Grosse, G., Michaelson, G. J., Koven, C. D., O’Donnell, J. A., Elberling, B., Mishra, U., Camill, P., Yu, Z., Palmtag, J., and Kuhry, P.: Estimated stocks of circumpolar permafrost carbon with quantified uncertainty ranges and identified data gaps, Biogeosciences, 11, 6573-6593, doi:10.5194/bg-11-6573-2014, 2014.

Jagdhuber, T., Stockamp, J., Hajnsek, I., and Ludwig, R.: Identification of Soil Freezing and Thawing States Using SAR Polarimetry at C-Band, Remote Sens., 6, 2008-2023, 2014.

Jeffries, M., Wakabayashi, H., and Weeks, W.: ERS-1 SAR backscatter changes associated with ice growing on shallow lakes in Arctic Alaska, in: International Geoscience and Remote Sensing Symposium, 4, 2001-2004, doi:10.1109/IGARSS.1993.322048, 1993.

Jones, M. C., Grosse, G., Jones, B. M., and Anthony, K. W.: Peat accumulation in drained thermokarst lake basins in continuous, ice-rich permafrost, northern Seward Peninsula, Alaska, J. Geophys. Res.-Biogeo., 117, G00M07, doi:10.1029/2011JG001766, 2012.

Lehner, B. and Döll, P.: Development and Validation of a Global Database of Lakes, Reservoirs and Wetlands, J. Hydrol., 296, 122, 2004.

Mishra, U. and Riley, W. J.: Alaskan soil carbon stocks: spatial variability and dependence on environmental factors, Biogeosciences, 9, 3637-3645, doi:10.5194/bg-9-3637-2012, 2012.

Mishra, U. and Riley, W. J.: Active-Layer Thickness across Alaska: Comparing Observation-Based Estimates with CMIP5 Earth System Model Predictions, Soil Sci. Soc. Am. J., 78, 894-902, 2014.

Naeimi, V., Paulik, C., Bartsch, A., Wagner, W., Kidd, R., Boike, J., and Elger, K.: ASCAT Surface State Flag (SSF): Extracting Information on Surface Freeze/Thaw Conditions from Backscatter Data Using an Empirical Threshold-Analysis Algorithm, IEEE Trans. Geosci. Remote Sens., 50, 2566-2582, 2012.

Oh, Y., Sarabandi, K., and Ulaby, F.: An empirical model of an inversion technique for radar scattering from bare soil surfaces, IEEE Trans. Geosci. Remote Sens., 30, 370-381, 1992.

Palmtag, J., Hugelius, G., Lashchinskiy, N., Tamstorf, M. P., Richter, A., Elberling, B., and Kuhry, P.: Storage, Landscape Distribution, and Burial History of Soil Organic Matter in Contrasting Areas of Continuous Permafrost, Arct. Antarct. Alp. Res., 47, 71-88, 2015.

Park, S.-E., Bartsch, A., Sabel, D., Wagner, W., Naeimi, V., and Yamaguchi, Y.: Monitoring Freeze/Thaw Cycles Using ENVISAT ASAR Global Mode, Remote Sens. Environ., 115, 3457-3467, 2011

Pathe, C., Wagner, W., Sabel, D., Doubkova, M., and Basara, J.: Using ENVISAT ASAR Global Mode Data for Surface Soil Moisture Retrieval Over Oklahoma, USA, IEEE T. Geosci. Remote, 47, 468-480, 2009.
Palmtag, J., Ramage, J., Hugelius, G., Gentsch, N., Lashchinskiy, N., Richter, A., and Kuhry, P.: Controls on the storage of organic carbon in permafrost soils in northern Siberia, Eur. J. Soil Sci., 67, 478-491, doi:10.1111/ejss.12357, 2016.

Paulik, C., Melzer, T., Hahn, S., Bartsch, A., Heim, B., Elger, K., and Wagner, W.: Circumpolar surface soil moisture and freeze/thaw surface status remote sensing products (version 2) with links to geotiff images and NetCDF files (2007-2001 to 2010-2009), doi:10.1594/PANGAEA.775959, 2012.

Ping, C.-L., Michaelson, G. J., Jorgenson, M. T., Kimble, J. M., Epstein, H., Romanovsky, V. E., and Walker, D. A.: High stocks of soil organic carbon in the North American Arctic region, Nat. Geosci., 1, 615-619, 2008.

Reschke, J., Bartsch, A., Schlaffer, S., and Schepaschenko, D.: Capability of C-Band SAR for Operational Wetland Monitoring at High Latitudes, Remote Sens., 4, 2923-2943, 2012.

Sabel, D., Bartalis, Z., Wagner, W., Doubkova, M., and Klein, J.P.: Development of a Global Backscatter Model in support to the Sentinel-1 mission design, Remote Sens. Environ., 120, 102$112,2012$.

Santoro, M., Beer, C., Cartus, O., Schmullius, C., Shvidenko, A., McCallum, I., Wegmüller, U., and Wiesmann, A.: Retrieval of growing stock volume in boreal forest using hyper-temporal series of Envisat ASAR ScanSAR backscatter measurements, Remote Sens. Environ., 115, 490-507, 2011.

Schuur, E., Bockheim, J., Canadell, J., Euskirchen, E., Field, C. B., Goryachkin, S. V., Hagemann, S., Kuhry, P., Lafleur, P., Lee, H., Mazhitova, G., Nelson, F. E., Rinke, A., Romanovsky, V., Shiklomanov, N., Tarnocai, C., Venevsky, S., Vogel, J. G., and Zimov, S. A.: Vulnerability of permafrost carbon to climate change: Implications for the global carbon cycle, BioScience, 58, 701-714, 2008.

Schuur, E. A. G., McGuire, A. D., Schadel, C., Grosse, G., Harden, J. W., Hayes, D. J., Hugelius, G., Koven, C. D., Kuhry, P., Lawrence, D. M., Natali, S. M., Olefeldt, D., Romanovsky, V. E., Schaefer, K., Turetsky, M. R., Treat, C. C., and Vonk, J. E.: Climate change and the permafrost carbon feedback, Nature, 520, 171-179, 2015.

Siewert, M. B., Hanisch, J., Weiss, N., Kuhry, P., Maximov, T. C., and Hugelius, G.: Comparing carbon storage of Siberian tundra and taiga permafrost ecosystems at very high spatial resolution, J. Geophys. Res.-Biogeo., 120, 1973-1994, 2015.

Tarnocai, C., Canadell, J. G., Schuur, E. A. G., Kuhry, P., Mazhitova, G., and Zimov, S.: Soil organic carbon pools in the northern circumpolar permafrost region, Global Biogeochem. Cy., 23, GB2023, doi:10.1029/2008GB003327, 2009.

Ulaby, F. and Stiles, W.: Microwave response of snow, Adv. Space Res., 1, 131-149, 1981.

Ulaby, F. T., Moore, R. K., and Fung, A.: Microwave Remote Sensing-Active and Passive, vol. II, Artech House, Norwood, Mass., 1982.

Ullmann, T., Schmitt, A., Roth, A., Duffe, J., Dech, S., Hubberten, H.-W., and Baumhauer, R.: Land Cover Characterization and Classification of Arctic Tundra Environments by Means of Polarized Synthetic Aperture X- and C-Band Radar (PolSAR) and Landsat 8 Multispectral Imagery - Richards Island, Canada, Remote Sens., 6, 8565-8593, 2014. 
Wagner, W., Lemoine, G., and Rott, H.: A Method for Estimating Soil Moisture from ERS Scatterometer and Soil Data, Remote Sens. Environ., 70, 191-207, 1999.

Wagner, W., Pathe, C., Doubkova, M., Sabel, D., Bartsch, A., Hasenauer, S., Blöschl, G., Scipal, K., Martínez-Fernández, J., and Löw, A.: Temporal Stability of Soil Moisture and Radar Backscatter Observed by the Advanced Synthetic Aperture Radar (ASAR), Sensors, 8, 1174-1197, 2008.

Walker, D., Gould, W., Maier, H., and Raynolds, M.: The Circumpolar Arctic Vegetation Map: AVHRR-derived base maps, environmental controls, and integrated mapping procedures, Int. J. Remote Sens., 23, 4551-4570, 2002.

Wang, X., Ge, L., and Li, X.: Pasture Monitoring Using SAR with COSMO-SkyMed, ENVISAT ASAR, and ALOS PALSAR in Otway, Australia, Remote Sens., 5, 3611, doi:10.3390/rs5073611, 2013.

Waring, R., Way, J., Hunt, R., Morrissey, L., Ranson, J., Weishampel, J., Oren, R., and Frankling, S.: Imaging radar for ecosystem studies, Bio-Science, 4, 715-723, 1995.

Weiss, N., Blok, D., Elberling, B., Hugelius, G., Jorgensen, C. J., Siewert, M. B., and Kuhry, P.: Thermokarst dynamics and soil organic matter characteristics controlling initial carbon release from permafrost soils in the Siberian Yedoma region, Sediment. Geol., 340, 38-48, doi:10.1016/j.sedgeo.2015.12.004, 2016.
Widhalm, B., Bartsch, A., and Heim, B.: A novel approach for the characterization of tundra wetland regions with C-band SAR satellite data, Int. J. Remote Sens., 36, 5537-5556, 2015 a.

Widhalm, B., Bartsch, A., and Heim, B.: Circumarctic wetland dataset based on ENVISAT ASAR Global Monitoring Mode with links to geotiff image and NetCDF files (2005-01 to 201112), doi:10.1594/PANGAEA.840548, Supplement to: A novel approach for the characterization of tundra wetland regions with C-band SAR satellite data, International Journal of Remote Sensing, 36, 5537-5556, doi:10.1080/01431161.2015.1101505, 2015b.

Woodhouse, I.: Introduction to Microwave Remote Sensing, Taylor \& Francis, New York, 2006.

Wulf, H., Mulder, T., Schaepman, M. E., Keller, A., and Jörg, P.: Remote Sensing of Soils, Tech. Rep., Remote Sensing Laboratories, University of Zürich, doi:10.13140/2.1.1098.0649, 2015. 